\title{
Fluorine-Rich Zinc Oxoclusters as Extreme Ultraviolet Photoresists: Chemical Reactions and Lithography Performance
}

\author{
Neha Thakur,* Michaela Vockenhuber, Yasin Ekinci, Benjamin Watts, Angelo Giglia, Nicola Mahne, \\ Stefano Nannarone, Sonia Castellanos, * and Albert M. Brouwer*
}

Cite This: ACS Mater. Au 2022, 2, 343-355

Read Online

ACCESS |

山ll Metrics \& More

回 Article Recommendations

Supporting Information

ABSTRACT: The absorption of extreme ultraviolet (EUV) radiation by a photoresist strongly depends on its atomic composition. Consequently, elements with a high EUV absorption cross section can assist in meeting the demand for higher photon absorbance by the photoresist to improve the sensitivity and reduce the photon shot noise induced roughness. In this work, we enhanced the EUV absorption of the methacrylic acid ligands of $\mathrm{Zn}$ oxoclusters by introducing fluorine atoms. We evaluated the lithography performance of this fluorine-rich material as a negative tone EUV photoresist along with extensive spectroscopic and microscopic studies, providing deep insights into the underlying mechanism. UV-vis spectroscopy studies demonstrate that the presence of fluorine in the oxocluster enhances its stability in the thin films to the ambient atmosphere. However, the

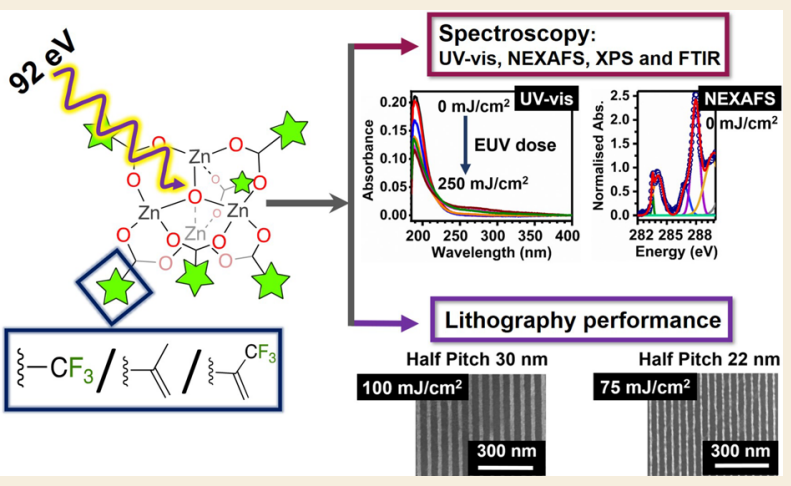
EUV photoresist sensitivity $\left(D_{50}\right)$ of the fluorine-rich oxocluster is decreased compared to its previously studied methacrylic acid analogue. Scanning transmission X-ray microscopy and in situ X-ray photoelectron spectroscopy in combination with FTIR and $\mathrm{UV}$-vis spectroscopy were used to gain insights into the chemical changes in the material responsible for the solubility switch. The results support decarboxylation of the ligands and subsequent radical-induced polymerization reactions in the thin film upon EUV irradiation. The rupture of carbon-fluorine bonds via dissociative electron attachment offers a parallel way of generating radicals. The mechanistic insights obtained here will be applicable to other hybrid materials and potentially pave the way for the development of EUV materials with better performance.

KEYWORDS: EUV photoresists, EUV lithography, STXM,NEXAFS, in situ XPS, infrared spectroscopy, UV spectroscopy

\section{INTRODUCTION}

The dimensions of the smallest components that can be fabricated using photolithography are directly proportional to the wavelength of the radiation used in the process. Over decades, the wavelength of the imaging light used in the semiconductor industry for photolithography has decreased from G-line $(436 \mathrm{~nm})$ to I-line $(365 \mathrm{~nm})$ to $\operatorname{KrF}(248 \mathrm{~nm})$ to $\operatorname{ArF}(193 \mathrm{~nm})$ immersion lithography (ArFi). ${ }^{1,2}$ Presently, extreme ultraviolet (EUV) at $13.5 \mathrm{~nm}$ has emerged as the successor of ArFi as next-generation lithography to reach the industry's objective of patterning feature sizes of $10 \mathrm{~nm}$ and below in a cost-effective manner.,

The steep jump in the wavelength from 193 to $13.5 \mathrm{~nm}$ has posed numerous challenges, and a key factor that will determine the future improvements of EUV lithography (EUVL) is the choice of the photoresist and its solubilityswitching chemistry. ${ }^{1,5,6}$ For UV lithography, organic materials are used as photoresists and their reactions are based on photochemical acid generation via electronically excited states. The photon energy of EUVL $(13.5 \mathrm{~nm}, \sim 92 \mathrm{eV})$, however, is $\sim 14 \times$ higher than that of its predecessor, ArF (193 nm, 6.4
$\mathrm{eV}$ ), and the EUV absorption mechanism and resulting chemical reactions are different. EUV photons are highly energetic and surpass the ionization potential of the material. Thus, EUV absorption by the material results in the ejection of photoelectron(s). These electrons have sufficiently high energy to further interact with the neighboring molecules in the thin film, giving rise to secondary electron processes. ${ }^{7-10}$ Thus, EUV photon absorption by the resist initiates a cascade of reactions in the thin films, ${ }^{6,8,11}$ and because of this complexity, understanding the fundamentals is challenging. Moreover, the deconvolution of these events is not straightforward, especially in the thin film samples. Henceforth, a fundamental understanding of the induced chemical changes or reaction path

Received: October 14, 2021

Revised: January 29, 2022

Accepted: January 31, 2022

Published: February 14, 2022

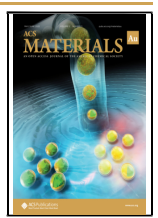


(a)

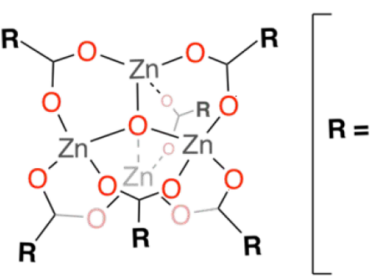

(c)

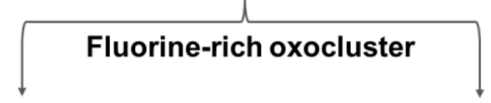

EUV lithography performance

(Contrast curves \& EUV-IL)

Comparison with

$\mathrm{Zn}(\mathrm{MA})(\mathrm{TFA})$ analogue

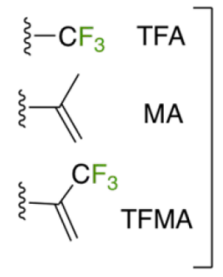

Spectroscopy studies on EUV exposed samples

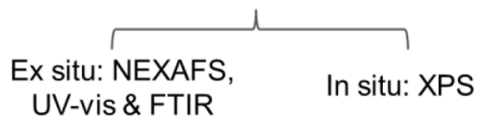

(b)

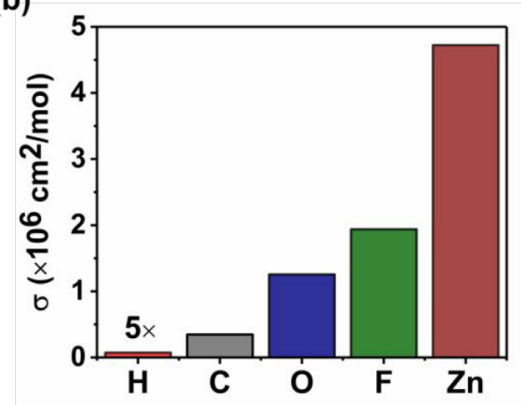

Reaction mechanism

Figure 1. (a) Schematic representation of $\mathrm{Zn}$ oxoclusters: fluorine-rich oxocluster $\mathrm{Zn}(\mathrm{TFMA})$ (average composition $\left.\mathrm{Zn}(\mathrm{TFMA})_{5.9}(\mathrm{TFA})_{0.1}\right)_{\text {and }}$ $\mathrm{Zn}$ (TFMA)(MA)(TFA) (average composition Zn(TFMA) ${ }_{2.4}(\mathrm{MA})_{2.9}(\mathrm{TFA})_{0.8}$ ) and the previously studied analogue, $\mathrm{Zn}(\mathrm{MA})_{5}$ (TFA) ${ }_{1}$. (b) EUV atomic absorption cross section at $92 \mathrm{eV}$ of elements $\mathrm{H}(\times 5), \mathrm{C}, \mathrm{O}, \mathrm{F}$, and $\mathrm{Zn}$ obtained from the CXRO database. ${ }^{24}$ (c) Schematic representation of the study flow for fluorine-rich $\mathrm{Zn}$ oxocluster for EUVL applications.

mechanisms upon irradiating the photoresist material with ionizing EUV radiation is crucial. ${ }^{12}$

The primary challenge posed by the conventional organic resists (mainly constituting $\mathrm{C}, \mathrm{H}$, and $\mathrm{O}$ ) is their low EUV absorption, and this drew the attention of researchers toward incorporating elements (especially metals) having a high photon absorption cross section at $92 \mathrm{eV}$ to potentially increase sensitivity and reduce stochastic effects. ${ }^{1,11,13-17}$ Our previous studies on a hybrid zinc-based oxocluster, $\mathrm{Zn}$ $(\mathrm{MA})_{5}(\mathrm{TFA})_{1}$ (MA is methacrylate ligand; TFA is trifluoroacetate ligand, Figure 1a), demonstrated an EUV linear absorption coefficient of $12 \mu \mathrm{m}^{-1}$, much higher than that of traditional organic photoresists $\left(\sim 5 \mu \mathrm{m}^{-1}\right) .{ }^{18}$ Further, mechanistic insights for the solubility switch in $\mathrm{Zn}$ (MA)(TFA) photoresist upon EUV exposure using spectroscopic studies demonstrated polymerization of the terminal double bonds of the MA ligands and formation of fluoride species in the thin films from TFA via dissociative electron attachment (DEA). ${ }^{19}$ The same reaction paths were found when the material was irradiated with low energy electrons of 20 and $80 \mathrm{eV}^{20}$

In this work, we study fluorine-rich $\mathrm{Zn}$-based oxoclusters, designed using the 2-(trifluoromethyl)acrylate (TFMA) ligand instead of MA. The terminal double bond of the ligand was kept intact to allow polymerization upon EUV irradiation, yet at the same time more fluorine was introduced. The molar absorption cross section of fluorine at $92 \mathrm{eV}$ is $\sim 26 \times$ larger than that of $\mathrm{H}$ and $\sim 5.6 \times$ that of $\mathrm{C}$ (Figure $1 \mathrm{~b}$ ). Hence, its incorporation, along with the metals, in the resist material has the potential to increase the EUV absorbance. Moreover, some studies have demonstrated an overall enhanced EUV lithography performance upon the incorporation of fluorine in the photoresist material. $9,21-23$

This work focuses on the detailed study of fluorine-rich $\mathrm{Zn}$ oxocluster for EUVL application (Figure 1c) mainly in two ways:

(i) investigating the changes in processability, stability of oxoclusters in thin films, and EUV lithography perform- ance upon fluorine incorporation in comparison with its previously studied $\mathrm{Zn}$ (MA)(TFA) analogue; ${ }^{19}$ and

(ii) monitoring chemical changes on the fluorine-rich zinc oxocluster thin films upon EUV irradiation using nearedge X-ray absorption fine structure (NEXAFS), FTIR and UV-vis spectroscopy, and X-ray photoelectron spectroscopy (XPS) studies.

For comparison, we include a mixed-ligand compound $\mathrm{Zn}$ (TFMA)(MA)(TFA) with average composition $\mathrm{Zn}$ (TFMA $)_{2.4}(\mathrm{MA})_{2.9}(\mathrm{TFA})_{0.8}$ in the study. The present studies reveal that the incorporation of more fluorine in methacrylate$\mathrm{Zn}$ oxoclusters is not a magic bullet. Replacing MA with TFMA did aid in increasing the thin film stability over time, but the formation of smooth thin films on substrates proved to be difficult. Although the EUV absorption of the fluorine-rich oxocluster $\mathrm{Zn}$ (TFMA) (Figure 1a) must be theoretically higher than that of its previously studied analogue $\mathrm{Zn}(\mathrm{MA})$ (TFA), the sensitivity $\left(D_{50}\right)$ for EUV lithography turns out to be unexpectedly lower. Spectroscopy studies show loss of $\mathrm{CO}_{2}$ from carboxylate ligands, and a strong decrease of $\mathrm{C}=\mathrm{C} / \mathrm{C}=$ $\mathrm{O}$ ratio as a function of EUV dose supports radical initiated polymerization in the thin film. Furthermore, fluorine migration from the $\mathrm{CF}_{3}$ groups toward $\mathrm{Zn}$ was observed, forming new $\mathrm{Zn}-\mathrm{F}$ species. This likely occurs via a dissociative electron attachment (DEA) path (low-energy electrons). We believe that the present results enhance our understanding of $\mathrm{Zn}$ based fluorine-rich photoresists and similar systems for lithography application and will propel advance focused investigations for fluorine-rich photoresist materials.

\section{EXPERIMENTAL DETAILS}

\subsection{Synthesis of Fluorine-Rich Zn Oxoclusters: Zn(TFMA) and $\mathrm{Zn}(\mathrm{TFMA})(\mathrm{MA})(\mathrm{TFA})$}

In this study, fluorine-rich oxoclusters were synthesized from a commercially available precursor having a $\mathrm{Zn}$ tetranuclear oxo-core and an organic shell of 6 trifluoroacetate (TFA) ligands, following the same exchange procedure as described in our previous work. ${ }^{18}$ The effect of fluorine incorporation in the reactive organic ligands of the 
Zn-oxocluster was studied by investigating $\mathrm{Zn}$ (TFMA) (still containing a minor fraction of TFA, average composition $\mathrm{Zn}$ $\left.(\text { TFMA })_{5.9}(\text { TFA })_{0.1}\right)$ and a similar cluster with a mixed ligand shell, $\mathrm{Zn}$ (TFMA)(MA)(TFA) (average composition $\mathrm{Zn}$ $(\text { TFMA })_{2.4}(\mathrm{MA})_{2.9}(\mathrm{TFA})_{0.8}$ ); see Figure 1a. The EUVL performance of the materials was compared to the previously studied analogue, $\mathrm{Zn}(\mathrm{MA})(\mathrm{TFA}){ }^{18,19}$

2.1.1. Synthesis of $\mathrm{Zn}(\mathrm{TFMA})$. Oxo[hexa(trifluoroacetato)] tetrazinc trifluoracetic acid adduct ( $\mathrm{Zn}$ (TFA); $500 \mathrm{mg}, 0.52 \mathrm{mmol}$, 1 equiv) and 2-(trifluoromethyl)acrylic acid (TFMAA; $870 \mathrm{mg}, 6.2$ mmol, 12 equiv) were dissolved in acetonitrile, and the solution was stirred for $5 \mathrm{~h}$ at $45{ }^{\circ} \mathrm{C}$. The remaining solvent was then evaporated using a rotary evaporator, and an oily residue was obtained. The residue was reprecipitated by adding toluene to it and evaporating the solvent on a rotary evaporator. The process was repeated four to five times to remove excess of acid and obtain a white solid product. This was dried in a vacuum oven at $40{ }^{\circ} \mathrm{C}$ and stored under nitrogen. The reaction scheme is shown in SI, Figure S1.

${ }^{1} \mathrm{H}$ NMR $\left(300 \mathrm{MHz}, \mathrm{DMSO}-d_{6}\right) \delta: 6.52\left(1 \mathrm{H},=\mathrm{CH}_{2}\right)$ and 6.30 $\left(1 \mathrm{H},=\mathrm{CH}_{2}\right)$, Figure $\mathrm{S} 2$.

${ }^{19} \mathrm{~F}$ NMR $\left(300 \mathrm{MHz}, \mathrm{DMSO}-d_{6}\right) \delta:-73.69\left(-\mathrm{CF}_{3}\right.$, TFA $)$ and $-63.92\left(-\mathrm{CF}_{3}, \mathrm{TFMA}\right)$; integration of 46.3 and 1.0 of peaks, respectively, showing that most of the TFA ligand in the precursor has been exchanged by TFMA and on average 5.9 TFMA ligand and 0.1 TFA ligand is present in the organic shell of $\mathrm{Zn}$ (TFMA) oxocluster, Figure S2.

FTIR: 695 ( $\mathrm{COO}$ angle bending), 828 ( $\mathrm{s}, \mathrm{CH}_{2}$ bending mode), 993 and 912 (bending out of plane, $\left.\gamma(\mathrm{CH}) \mathrm{C}=\mathrm{CH}_{2}\right), 1130$ and 1167 ( $\nu \mathrm{C}-\mathrm{F}), 1380-1487\left(\mathrm{CH}_{x}+\nu_{\mathrm{s}} \mathrm{COO}\right), 1583\left(\nu_{\mathrm{as}} \mathrm{COO}(\mathrm{TFMA})\right)$, 1631 ( $\nu \mathrm{C}=\mathrm{C}$ (TFMA) monodentate), $1660(\nu \mathrm{C}=\mathrm{C})$ and 1678 $\mathrm{cm}^{-1}$ ( $\nu_{\text {as }}$ COO (TFMA) monodentate); spectra shown in SI (Figure S3).

Mass spectrometry: the observed isotopic distribution corresponds to the presence of the tetranuclear $\mathrm{Zn}$ core of the oxocluster (Figure S4). The $\mathrm{Zn}$ oxocluster is susceptible to form complexes with acetonitrile (electrospray solvent), also observed in our previous studies. $^{18,25}$ The isotopic distribution observed in the mass spectra was assigned to the oxocluster complex: $\mathrm{Zn}_{4} \mathrm{O}$ with 5 TFMA ligands and $2 \mathrm{CH}_{3} \mathrm{CN}$ molecules, which is in concordance with simulated spectra using ChemCal. ${ }^{26}$

The deposition of the thin films on substrates of $\mathrm{Zn}$ (TFMA) was done by spin coating $2 \mathrm{w} / \mathrm{v} \%$ of resist solution from $\mathrm{CHCl}_{3}$ : PGMEA $(7: 3, v / v)$. All thin films were spin-coated at an acceleration of 3000 $\mathrm{rpm} / \mathrm{s}$ and $2100 \mathrm{rpm}$ speed for $30 \mathrm{~s}$ immediately followed by postapplication bake $(\mathrm{PAB})$ at $90^{\circ} \mathrm{C} / 30 \mathrm{~s}$. The thickness of the thin films obtained using the above parameters on Si substrates is $14-20$ $\mathrm{nm}$, determined by atomic force microscopy (AFM), using a Bruker ScanAsyst-air probe.

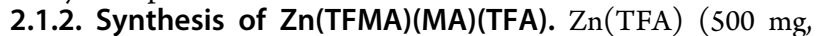
$0.52 \mathrm{mmol}, 1$ equiv), 2-(trifluoromethyl)acrylic acid (TFMAA; 270 $\mathrm{mg}, 3.1 \mathrm{mmol}, 6$ equiv), and methacrylic acid (MAA; $440 \mathrm{mg}, 3.1$ mmol, 6 equiv) were used as precursors for the reaction, and the same synthesis procedure as described above for the $\mathrm{Zn}$ (TFMA) synthesis was used with acetonitrile as the solvent.

${ }^{1} \mathrm{H}$ NMR (300 MHz, DMSO- $\left.d_{6}\right) \delta: 6.52\left(1 \mathrm{H},=\mathrm{CH}_{2}\right.$, TFMA), $6.30\left(1 \mathrm{H},=\mathrm{CH}_{2}\right.$, TFMA $), 5.85\left(1 \mathrm{H},=\mathrm{CH}_{2}, \mathrm{MA}\right), 5.36(1 \mathrm{H},=$ $\left.\mathrm{CH}_{2}, \mathrm{MA}\right)$ and $1.85\left(-\mathrm{CH}_{3}, \mathrm{MA}\right)$; integration of $2.4\left(2 \mathrm{H},=\mathrm{CH}_{2}\right.$, TFMA $), 2.0\left(2 \mathrm{H},=\mathrm{CH}_{2}, \mathrm{MA}\right)$ and $3.1\left(-\mathrm{CH}_{3}, \mathrm{MA}\right)$ was obtained for peaks, Figure S5.

${ }^{19} \mathrm{~F}$ NMR (300 MHz, DMSO- $\left.d_{6}\right) \delta:-73.58\left(-\mathrm{CF}_{3}\right.$, TFA $)$ and $-63.85\left(-\mathrm{CF}_{3}, \mathrm{TFMA}\right)$; integration of 0.30 and 1.0 was obtained for peaks, respectively, Figure S5.

From the ${ }^{1} \mathrm{H}$ and ${ }^{19} \mathrm{~F}$ NMR analysis of $\mathrm{Zn}$ (TFMA)(MA)(TFA) oxocluster, the composition of the organic shell was determined as an average of 2.4 TFMA, 2.9 MA, and 0.8 TFA. The deposition of the thin films of the $\mathrm{Zn}$ (TFMA)(MA)(TFA) oxocluster was done by spin coating $\mathrm{CHCl}_{3}$ :PGMEA $(7: 3, \mathrm{v} / \mathrm{v})$ as the casting solvent for $2 \mathrm{w} / \mathrm{v} \%$ of resist solution. All thin films were spin-coated at an acceleration of $3000 \mathrm{rpm} / \mathrm{s}$ and $2100 \mathrm{rpm}$ speed for $30 \mathrm{~s}$ followed by immediate postapplication bake $(\mathrm{PAB})$ at $90{ }^{\circ} \mathrm{C} / 30 \mathrm{~s}$.

\subsection{Silanization Process}

Clean Si substrates were treated with an ozone photoreactor to maximize the reactive terminal hydroxyl groups on the $\mathrm{Si}$ substrate surface, immediately followed by a silanization process. Silanes used in this study were: 3-(chloropropyl)triethoxysilane, 3-(mercaptopropyl)trimethoxysilane, 3-(triethoxysilyl)propyl methacrylate, 3(aminopropyl)triethoxysilane, 1H,1H,2H,2H-perfluorooctyltriethoxysilane, and bis(trimethylsilyl)amine (HMDS). Silanization was carried out in the liquid phase except for HMDS which was deposited in the vapor phase. For liquid phase silanization, a reaction mixture was prepared in $80 \mathrm{~mL}$ of $96 \%$ ethanol to which a catalytic amount of $99 \%$ acetic acid was added to adjust the $\mathrm{pH}$ of the solution at $\sim 6$. To this solution, $2 \mathrm{~mL}$ of silane was added, and the clean treated Si substrates were placed in the reaction solution for $\sim 40 \mathrm{~min}$ at room temperature with constant stirring, washed with ethanol (96\%), and dried with nitrogen. The silanized substrates were annealed in an oven at ambient pressure, $130{ }^{\circ} \mathrm{C} / 24 \mathrm{~h}$.

\subsection{Sample Preparation}

Two types of substrates were used for near edge X-ray absorption fine structure (NEXAFS) measurements on $\mathrm{Zn}$ (TFMA) samples: (1) for reference (unexposed) spectra, a $5 \times 5 \mathrm{~mm}^{2}$ substrate with an array of $5 \times 5$ free-standing $\operatorname{SiN}_{x}$ windows $\left(0.15 \times 0.15 \mathrm{~mm}^{2}\right)$ was used; and (2) for EUV exposure $7.5 \times 7.5 \mathrm{~mm}^{2}$ substrates with a $\mathrm{SiN}_{x}$ membrane window (30 nm thick) of $3 \times 3 \mathrm{~mm}^{2}$ was used. $\mathrm{Zn}$ (TFMA) was spin coated on the membrane and exposed to EUV photons at different doses (exposed area of $0.5 \times 0.5 \mathrm{~mm}^{2}$ per dose) on a single $\mathrm{SiN}_{x}$ membrane window $\left(3 \times 3 \mathrm{~mm}^{2}\right)$. The measurements were performed in transmission mode.

For FTIR spectroscopy, thin films were spin coated on double side polished Si substrates ( $200 \mu \mathrm{m}$ thick) while for UV-vis analysis the thin films were spin coated on quartz substrates (500 $\mu$ m thick). For the XPS study, oxocluster was spin coated on the Si substrate sputter coated with $\mathrm{Cr} / \mathrm{Au}(5 \mathrm{~nm} / 40 \mathrm{~nm})$. Thin films for the contrast curves and EUV-IL experiments were spin coated on $\mathrm{Si}$ substrates (with native oxide layer) without any prior treatment. The thickness of the thin films spin coated using parameters mentioned above (section 2.1) on $\mathrm{Si} / \mathrm{SiO}_{2}$ (for EUV-IL, FTIR and XPS) and quartz substrates (UV-vis) are in the range of 14-20 nm. Remaining thin film thicknesses after development on the $\mathrm{SiN}_{x}$ substrate for STXM studies are shown in the Supporting Information (SI), Figure S16.

\subsection{EUV Exposure}

EUV (13.5 nm) exposures were performed using synchrotron radiation at the Paul Scherrer Institute (PSI), Switzerland at the Swiss Light Source XIL-II beamline for contrast curves, L/S features (EUV-interference lithography, EUV-IL), ${ }^{27,28}$ and ex situ spectroscopy measurements. Open frame exposures for contrast curves and NEXAFS measurements were performed over a range of doses, using a $0.5 \times 0.5 \mathrm{~mm}^{2}$ aperture mask. For FTIR and UV-vis spectroscopy studies exposures were done using a $1.7 \times 1.7 \mathrm{~mm}^{2}$ aperture mask. EUV-IL was used to test nanopatterning performance using a mask with periodic line/space (L/S) half-pitch (HP) of $50 \mathrm{~nm}, 40 \mathrm{~nm}, 30$ and $22 \mathrm{~nm}$.

\subsection{Postexposure Analysis and Ex Situ Spectroscopy Study}

A scanning transmission X-ray microscope (STXM) (PolLux beamline ${ }^{29}$ at PSI) was used to perform NEXAFS spectroscopy measurements as illustrated in Figure S6. The measurements were done under normal incidence using a line scan over a length of $25 \mu \mathrm{m}$. The beam was defocused to a spot size of $\sim 1 \mu \mathrm{m}$ to avoid radiation damage. For each energy, a sample scan was made on the sample, exposed to EUV, and developed using diluted $0.1 \%$ propionic acid in 2-heptanone for $10 \mathrm{~s}$ and a reference scan was made on a nearby area on the $\mathrm{SiN}_{x}$ membrane that was cleaned (unexposed photoresist, AFM images shown in Figure S17) by the development. Carbon Kedge spectra were recorded for an energy range of $270-350 \mathrm{eV}$ with an energy resolution of $0.35 \mathrm{eV}$. For F K-edge measurements, the energy was scanned from 675 to $710 \mathrm{eV}$. By repeating scans at the 
same sample area, we could show that radiation damage is negligible under these conditions. ATHENA software was used for spectra normalization and fitting of the $\mathrm{C}$ K-edge and $\mathrm{F}$ K-edge.

UV-vis spectroscopy was performed on thin films deposited on quartz using a Shimadzu UV2600 spectrophotometer, and FTIR was performed in transmission mode under vacuum using a Bruker Vertex $80 \mathrm{v}$ spectrometer. The samples for UV-vis and FTIR spectroscopy were not developed after exposure.

A Bruker Dimension Icon atomic force microscope was used for thickness measurements to obtain contrast curves and inspect the thin film quality or line/space (L/S) pattern printed on Si substrates in Bruker ScanAsyst-air mode.

Top-down scanning electron microscopy (SEM) images of L/S patterns were recorded using a FEI Verios 460 scanning electron microscope operating at a current of $100 \mathrm{pA}$ and a voltage of $5.0 \mathrm{kV}$.

\subsection{In Situ XPS Study}

EUV exposure and XPS measurements were performed at the BEAR beamline of the ELETTRA synchrotron radiation facility, at a base pressure of $10^{-9}$ mbar. $^{30,31}$ A sample was exposed to $92 \mathrm{eV}$ for a range of doses at different spots $\left(\sim 70 \times 300 \mu \mathrm{m}^{2}\right)$, and subsequently, XPS was measured at the exposed spots. The light at $13.5 \mathrm{~nm}$ was linearly polarized light, with the monochromator (vertical slit $50 \mu \mathrm{m}$ ) set for maximum throughput and using a silicon filter for higher order rejection. High-resolution XPS was acquired with the full beam and no filter. The incident dose at $92 \mathrm{eV}$ was determined in a separate scan by measuring the number of photons reaching the sample with the same beamline parameters used for the exposure using an absolute photodiode (AUXUV100 by OptoDiode corp.). The binding energy (BE) of the core levels were referenced to the $\mathrm{C}-\mathrm{F}$ peak at $292.81 \mathrm{eV}$ for $\mathrm{C}(1 \mathrm{~s})$ and $688.21 \mathrm{eV}$ for $\mathrm{F}(1 \mathrm{~s})$ as an internal reference to calibrate the $\mathrm{BE}$ scale of each spectrum. ${ }^{19} \mathrm{~A}$ bias of $-50 \mathrm{eV}$ was applied to the sample. A pass energy of $10 \mathrm{eV}$ for the electron analyzer and a step size of $0.2 \mathrm{eV}$ were used. XPS was acquired for $\mathrm{C}(1 \mathrm{~s}), \mathrm{O}(1 \mathrm{~s})$, and $\mathrm{F}(1 \mathrm{~s})$ with photon energies of 400,650 , and $800 \mathrm{eV}$, respectively, and fresh spots on the thin films were used for each exposure followed by XPS measurements. The XPS spectra were fitted using UNIFIT 2008 software.

\section{RESULTS AND DISCUSSION}

\subsection{Processability and Stability Studies}

Compared to the previously studied $\mathrm{Zn}(\mathrm{MA})$ (TFA), the solubility of the new fluorine-rich oxocluster $\mathrm{Zn}$ (TFMA) was increased in most organic solvents, especially in $\mathrm{CHCl}_{3}$ which was used for casting thin films. In the case of $\mathrm{Zn}(\mathrm{MA})$ (TFA), a saturated solution $\left(2 \mathrm{w} / \mathrm{v} \%\right.$ in $\mathrm{CHCl}_{3}:$ PGMEA, 9:1 v/v) had to be used, which limited the control over the film thickness of the resist. The increased solubility of fluorine-rich $\mathrm{Zn}$ (TFMA) allows for varying the thickness of the thin resist films.

In addition, the stability of fluorine-rich $\mathrm{Zn}$ (TFMA) thin films to ambient conditions was also enhanced. Since some studies presented in our work are conducted ex situ, the material stability over time plays a vital role for analysis. To track the chemical changes in the terminal double bond ( $\pi$ to $\pi^{*}$ transition, $\sim 190 \mathrm{~nm}$ ) of the TFMA ligand under ambient conditions, UV-vis spectroscopy was used. The absorption band of the double bond hardly changes for up to $5 \mathrm{~h}$ (shown in Figure S8) at ambient conditions. Some loss of absorption was observed after $7 \mathrm{~h}$, possibly due to polymerization of the double bonds Moreover, the absorption band shape was not severely affected as was observed in the case of its analogue $\mathrm{Zn}(\mathrm{MA})(\mathrm{TFA}) .{ }^{18}$ This increase in the stability of $\mathrm{Zn}$ (TFMA) thin film over its analogue $\mathrm{Zn}$ (MA)(TFA) can be attributed to the more hydrophobic nature of the material due to the presence of fluorine and the high electronegativity of the fluorine decreasing the effective electron density on the double bond, thus slowing the homopolymerization reaction.

\subsection{Thin Films and EUV Contrast Curves}

Thin films of the trifluoromethacrylate-containing $\mathrm{Zn}$ oxoclusters could be used for EUV exposure experiments, but they showed irregularities (Figure S11) that are probably related to poor adhesion to the substrate. Efforts were made to prevent this undesirable behavior by varying the surface energy of the substrate prior to spin coating by functionalization using silanes: 3-(mercaptopropyl)trimethoxysilane, 3(triethoxysilyl)propyl methacrylate, 3-(aminopropyl)triethoxysilane, and 3-(chloropropyl)triethoxysilane. Water contact angles $\left(\Theta_{c}\right)$ of the substrates coated with these silanes were $26,44,46$, and $65^{\circ}$, respectively. Unfortunately, none of these attempts led to the formation of high-quality thin films (Figure S9). In addition to the silanes mentioned above, Si surfaces were functionalized/modified using $1 \mathrm{H}, 1 \mathrm{H}, 2 \mathrm{H}, 2 \mathrm{H}$ perfluorooctyltriethoxysilane $\left(\Theta_{c}=80^{\circ}\right)$, HMDS, and hydrogen fluoride (HF, 2\%; dip for $1 \mathrm{~min}$ ), but no continuous thin film was obtained on the modified substrates.

The incorporation of fluorine in the resist material was anticipated to increase the EUV absorption of the material, which is expected to improve the EUVL performance of the photoresist. The EUV absorption coefficient of the $\mathrm{Zn}$ oxoclusters was estimated from the elemental absorption cross section at $92 \mathrm{eV}$ using the CXRO database and the relative amount of each element in the oxocluster, and the estimated density. ${ }^{32,33}$ The density of the $\mathrm{Zn}$ (TFMA) and $\mathrm{Zn}$ (MA)(TFA) oxoclusters was estimated using the molecular weight of the respective oxocluster and its CPK molecular volume calculated using Spartan 18. A scaling factor of 2 was used, based on the comparison of calculated and experimental densities for the acetate and pivalate clusters. ${ }^{34,35}$ The estimated EUV absorption coefficient obtained through this for $\mathrm{Zn}$ (TFMA) and its analogue $\mathrm{Zn}$ (MA)(TFA) are 14.3 and $10.6 \mu \mathrm{m}^{-1}$, respectively. The latter agrees well with the experimentally determined value of $12.4 \mu \mathrm{m}^{-1}$. $^{18}$

The sensitivities of the fluorine-rich oxoclusters for EUV photons were quantified experimentally using the contrast curves (exemplified in Figure 2) and were compared to their analogue $\mathrm{Zn}$ (MA)(TFA) which exhibited high sensitivity in our previous studies. The performance of the $\mathrm{Zn}$ (TFMA)(MA)(TFA) oxocluster was also studied using contrast curves and is shown in SI Figure S10. Table 1 summarizes the results from contrast curves of three $\mathrm{Zn}$-oxoclusters with increasing fluorine content: $\mathrm{Zn}$ (MA)(TFA), ${ }^{18} \mathrm{Zn}$ (TFMA)(MA)(TFA) (Figure S10) and $\mathrm{Zn}$ (TFMA) (Figure 2). For direct comparison here the contrast curves were only compared for the samples developed by using diluted propionic acid in $\mathrm{CHCl}_{3}$. Unexpectedly, the studies using contrast curves revealed that the overall EUVL performance of the new fluorine-rich $\mathrm{Zn}$ oxoclusters was not enhanced. It was observed that the sensitivity (dose for $50 \%$ thickness loss, $D_{50}$ ) and the contrast $(\gamma)^{36}$ of the fluorine-rich oxocluster, $\mathrm{Zn}$ (TFMA), $D_{50}$ $=40 \mathrm{~mJ} / \mathrm{cm}^{2}$ and $\gamma=1.71$, was decreased as compared to its analogue $\mathrm{Zn}$ (MA)(TFA), $D_{50}=3.3-10.8 \mathrm{~mJ} / \mathrm{cm}^{2}$ and $\gamma=$ 2.95-0.95.

This decrease in the sensitivity could arise from various factors. The electron density on the terminal double bond of TFMA ligand is relatively low because of the neighboring electron-withdrawing $\mathrm{CF}_{3}$ group. ${ }^{37}$ Previous studies have shown that introduction of a $-\mathrm{CF}_{3}$ group at the $\alpha$ position 


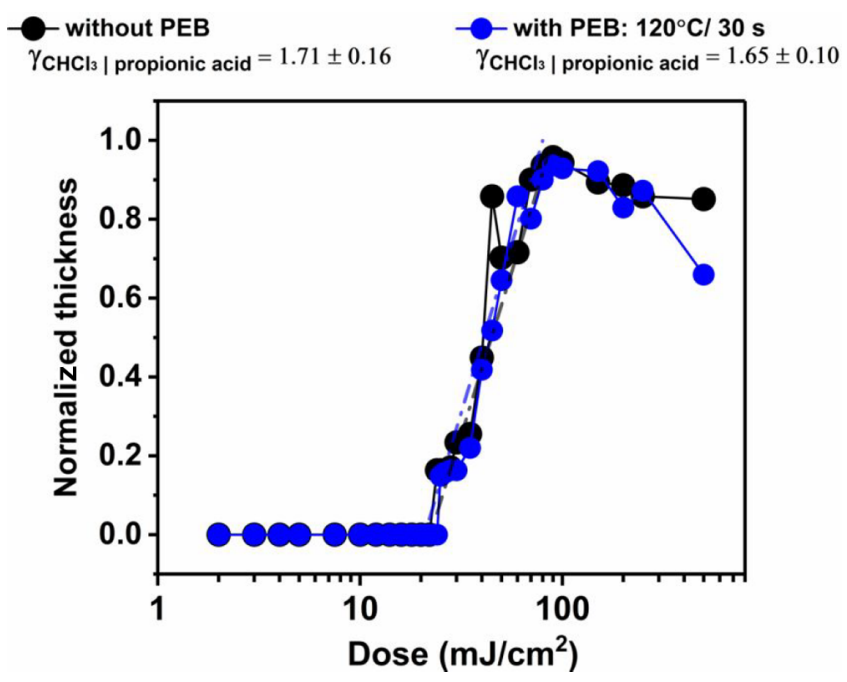

Figure 2. Contrast curves for $\mathrm{Zn}$ (TFMA) thin films using $\mathrm{CHCl}_{3}: \mathrm{PGMEA}$ as the casting solvent and developed using propionic acid $(0.05 \%)$ in $\mathrm{CHCl}_{3}$ for $8 \mathrm{~s}$. The thicknesses are normalized relative to the thickness of the unexposed thin film $(\sim 14 \mathrm{~nm})$. The contrast values $\gamma$ are the slopes of the curves between $D_{0}$ and $\sim D_{90}$.

Table 1. Comparison of Sensitivity $\left(D_{50}\right)$ and contrast $(\gamma)$ of the Three Zn-Based Oxoclusters for EUV Lithography Performance without and with Postexposure Bake (PEB) and Developed Using Diluted Propionic Acid in $\mathrm{CHCl}_{3}{ }^{a}$

\begin{tabular}{|c|c|c|}
\hline \multirow[b]{2}{*}{ material } & \multicolumn{2}{|c|}{ without PEB } \\
\hline & $D_{50}\left(\mathrm{~mJ} / \mathrm{cm}^{2}\right)$ & contrast $(\gamma)$ \\
\hline $\mathrm{Zn}(\mathrm{MA})(\mathrm{TFA})^{18}$ & $3.3-10.8$ & $2.95-0.95$ \\
\hline $\mathrm{Zn}(\mathrm{TFMA})(\mathrm{MA})(\mathrm{TFA})$ & 40.6 & 3.10 \\
\hline \multirow[t]{2}{*}{$\mathrm{Zn}$ (TFMA) } & 40.0 & 1.71 \\
\hline & \multicolumn{2}{|c|}{ with PEB } \\
\hline \multirow[t]{2}{*}{ material } & $D_{50}\left(\mathrm{~mJ} / \mathrm{cm}^{2}\right)$ & contrast $(\gamma)$ \\
\hline & \multicolumn{2}{|c|}{$100{ }^{\circ} \mathrm{C} / 30 \mathrm{~s}$} \\
\hline \multirow[t]{2}{*}{$\mathrm{Zn}(\mathrm{MA})(\mathrm{TFA})^{18}$} & 6.4 & 0.92 \\
\hline & \multicolumn{2}{|c|}{$120^{\circ} \mathrm{C} / 30 \mathrm{~s}$} \\
\hline \multirow[t]{2}{*}{$\mathrm{Zn}(\mathrm{TFMA})(\mathrm{MA})(\mathrm{TFA})$} & 50.5 & 3.01 \\
\hline & \multicolumn{2}{|c|}{$120^{\circ} \mathrm{C} / 30 \mathrm{~s}$} \\
\hline $\mathrm{Zn}$ (TFMA) & 45.0 & 1.65 \\
\hline
\end{tabular}

${ }^{a_{T}}$ The concentration of the propionic acid used is mentioned in their respective contrast curve figures.

decreases the rate of radical homopolymerization of the TFMA unit. $^{38,39}$ Different molecular packing of the oxoclusters in $\mathrm{Zn}$ (TFMA) compared to its analogue $\mathrm{Zn}(\mathrm{MA})(\mathrm{TFA})$ or a reduced ratio of the solubility rates of the unexposed and exposed regions in the developer of choice can also contribute toward this observed decrease in the sensitivity. Therefore, incorporation of more fluorine does not always directly translate into better EUVL performance of the photoresist, in contrast to the previous reported studies. ${ }^{23,40}$ Further, contrast curve studies demonstrated that postexposure bake (PEB) applied at $120^{\circ} \mathrm{C} / 30 \mathrm{~s}$ under ambient conditions led to a further slight decrease in the sensitivity (also see section 3.4). Spectroscopic studies to identify the chemical changes induced by $\mathrm{PEB}$ in the oxocluster were also carried out, and are discussed in section 3.7.

\subsection{EUV-IL Performance of Fluorine-Rich Zn Oxoclusters}

EUV-IL experiments were performed on $\mathrm{Zn}$ (TFMA) and $\mathrm{Zn}$ (TFMA)(MA)(TFA) oxoclusters to print L/S patterns of HP $50 \mathrm{~nm}, 40 \mathrm{~nm}, 30$ and $22 \mathrm{~nm}$. Selected SEM images of L/S patterns printed in $\mathrm{Zn}$ (TFMA) using EUV-IL and developed using diluted propionic acid in $\mathrm{CHCl}_{3}$ and with 2-heptanone are shown in Figures 3 and S15, respectively. Irregularities in the films can be seen along with scumming (residual resist between lines) and bridging between the printed lines. The decrease in the sensitivity demonstrated via contrast curve measurements is also observed here. The $\mathrm{L} / \mathrm{S}$ patterns printed with the fluorine-rich oxocluster are only observed at a relatively higher dose than required for its analogue $\mathrm{Zn}(\mathrm{MA})$ (TFA). ${ }^{19}$

The $\mathrm{Zn}$ (TFMA)(MA)(TFA) oxocluster was studied with EUV-IL in the same way as $\mathrm{Zn}$ (TFMA). Figures S12-S14 show selected SEM and AFM images of L/S features of HP 50, 40, 30, and $22 \mathrm{~nm}$ developed using both 2-heptanone and diluted propionic acid in $\mathrm{CHCl}_{3}$. The SEM and AFM images show considerable scumming after development also in this case.

\subsection{Effect of PEB on EUV-IL Performance}

Application of postexposure bake (PEB) did not lead to improvement in the EUV-IL performance for both $\mathrm{Zn}$ (TFMA)(MA)(TFA) and Zn(TFMA) oxocluster $\left(120{ }^{\circ} \mathrm{C} /\right.$ $30 \mathrm{~s})$. On the contrary, the application of $\mathrm{PEB}$ enhanced crystallization, bridging and scumming in L/S patterns. Figure $\mathrm{S} 16$ compares the performance of $\mathrm{Zn}$ (TFMA) oxocluster with and without PEB at the same dose of $75 \mathrm{~mJ} / \mathrm{cm}^{2}$.

Although the thin films show irregularities upon spin coating, the chemical changes induced by exposure to EUV irradiation can be studied using different spectroscopic techniques. Ex situ STXM-NEXAFS, FTIR, and UV-vis spectroscopy and in situ XPS studies were used to gain insights into the chemical changes in $\mathrm{Zn}$ oxoclusters as a function of the EUV dose. To monitor the chemical changes induced by EUV irradiation, the spectroscopic studies were focused on fluorine-rich $\mathrm{Zn}$ (TFMA) oxocluster.

\subsection{STXM Measurements}

To gain insights into the chemical changes upon EUV exposure in fluorine-rich $\mathrm{Zn}$ (TFMA) oxocluster, ex situ Xray absorption spectroscopy (XAS) studies were performed using the STXM at the PolLux beamline at PSI. ${ }^{29,41,42}$ The changes in the material as a function of EUV dose were observed especially in the near-edge region of the $\mathrm{C} \mathrm{K}$-edge spectra as it provides quantitative information on the types and amount of covalent bonding present in organic components. The spectra were measured in transmission mode, and thus, the whole thin film thickness was probed. Chemical changes in the material upon applied doses of 25,50 , and $250 \mathrm{~mJ} / \mathrm{cm}^{2}$ were monitored. The remaining thickness after development and quality of the exposed area on the $\mathrm{SiN}_{x}$ membrane after development was inspected using AFM, shown in SI Figure S17.

All the spectra were normalized to the continuum above $\sim 310 \mathrm{eV}$. The interpretation of the spectra was based on the "building-block model", and hence, the molecular oxocluster was considered as being composed of the individual local units. $^{43-45}$ In the fitting procedure, the step function representing the ionization to the continuum ${ }^{46,47}$ was represented by three steps corresponding to the $\mathrm{C}-\mathrm{C} / \mathrm{C}-\mathrm{H}$ $(292.0 \mathrm{eV}),-\mathrm{COO}(294.9 \mathrm{eV})$, and $-\mathrm{C}-\mathrm{F}(298.3 \mathrm{eV})$ units 
(a) $50 \mathrm{~nm}$

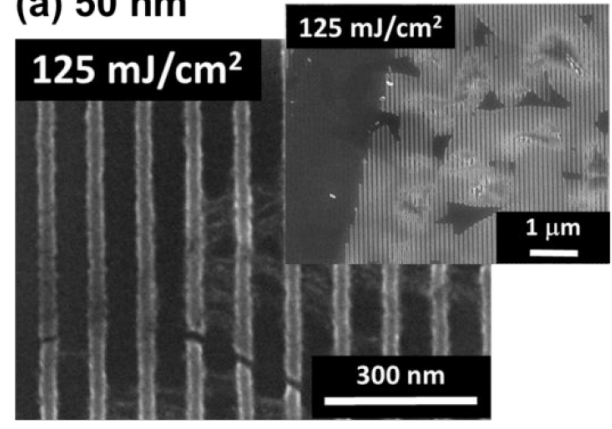

(c) $30 \mathrm{~nm}$

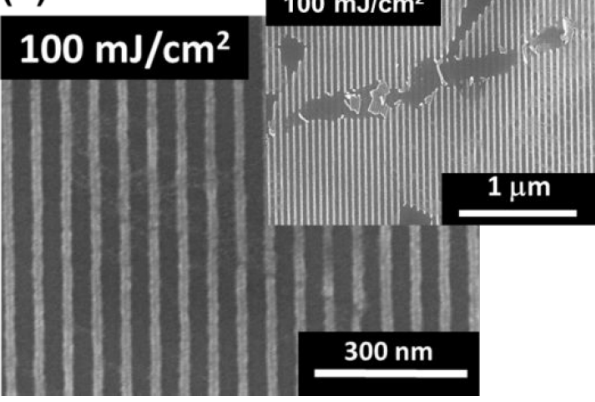

(b) $40 \mathrm{~nm}$

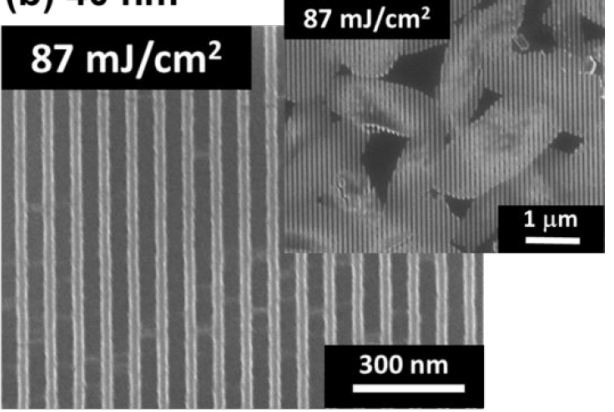

(d) $22 \mathrm{~nm}$

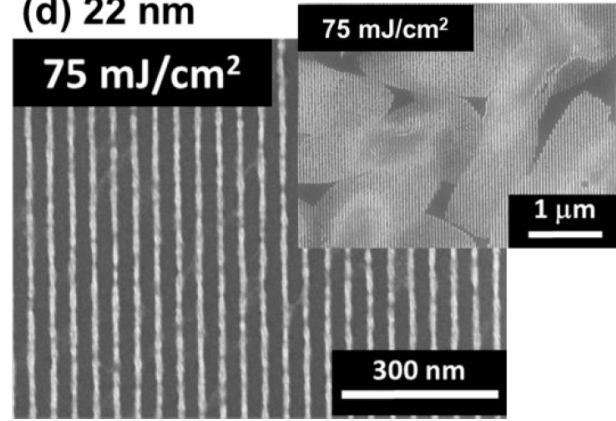

Figure 3. SEM images of L/S patterns of half-pitch: (a) $50 \mathrm{~nm}$, (b) $40 \mathrm{~nm}$, (c) $30 \mathrm{~nm}$, and (d) 22 nm, printed using EUV-IL exposures on $\mathrm{Zn}$ (TFMA) oxocluster and developed using diluted propionic acid $(0.1 \%)$ in 2-heptanone $(10 \mathrm{~s})$. The inset images show the irregularities of the thin film (zoom out).

(a)

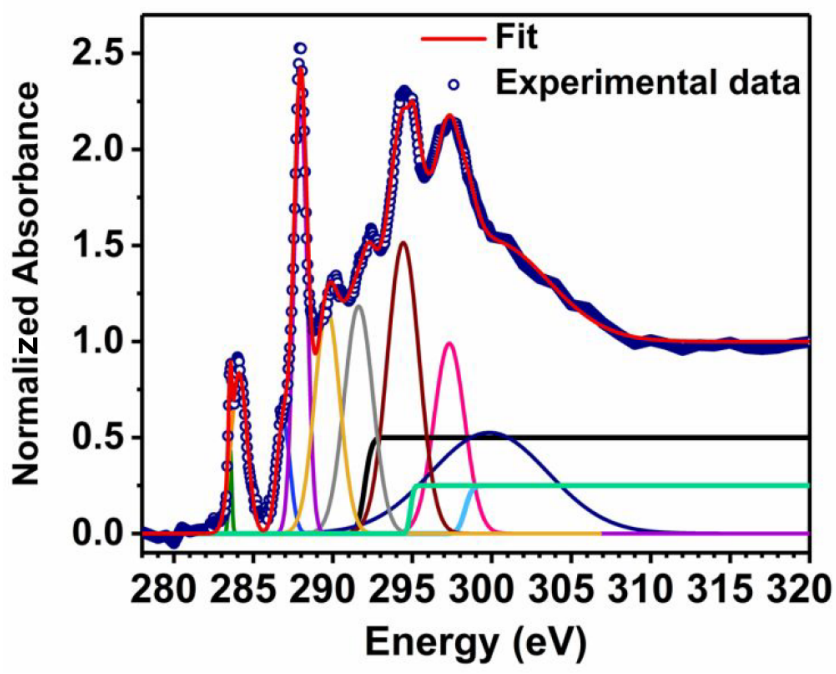

(b)

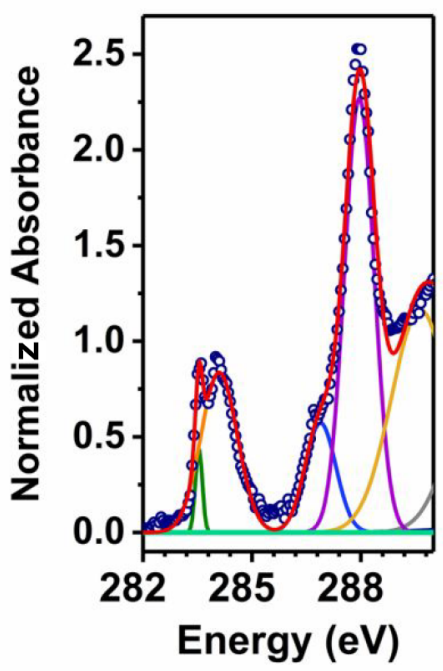

Figure 4. STXM-XAS C K-edge spectra of an unexposed Zn(TFMA) thin film: (a) complete spectrum and (b) zoom-in on the low-energy features.

of the Zn-oxocluster, which have characteristically different binding energies, as discussed below.

The fitted spectra of the reference (unexposed) sample of Zn(TFMA), shown in Figure 4, presents clear, sharp peaks at 284.2 and $284.7 \mathrm{eV}$. Quantum chemical calculations (see the SI for details) indicate that these correspond to the electronic transitions from $\mathrm{C}(1 \mathrm{~s})$ orbitals on $\mathrm{C} 1$ and $\mathrm{C} 2$ to the lowest unoccupied $\mathrm{MO}$, which is a $\pi^{*}$ orbital delocalized over the $\mathrm{C}=\mathrm{C}-\mathrm{C}=\mathrm{O}$ unit $\left(\mathrm{C}(1 \mathrm{~s}) \rightarrow \pi^{*}{ }_{\mathrm{C}=\mathrm{C}-\mathrm{C}=\mathrm{O}}\right)$ (Figure S20). The strong absorption at $287.9 \mathrm{eV}$ and the shoulder at $286.8 \mathrm{eV}$ are mainly due to transitions from $\mathrm{C}(1 \mathrm{~s})$ of $\mathrm{C} 1, \mathrm{C} 2$, and $\mathrm{C} 3$ to the next higher $\pi^{*}$ MO (Figure S20). The peaks at higher energies are not assigned here; they represent a complex mix of transitions involving $\sigma^{*}$ and Rydberg orbitals. ${ }^{48-51}$

Upon conversion due to EUV irradiation, the peaks at 284.2 and $284.7 \mathrm{eV}$ decrease in intensity relative to the main peak at $286.8 / 287.9 \mathrm{eV}$. This is consistent with the disappearance of the $\mathrm{C}=\mathrm{C}$ bonds due to cross-linking reactions. In the reaction product, the $\mathrm{C}=\mathrm{O}$ bond remains and the LUMO becomes the localized $\pi^{*}{ }_{\mathrm{C}=\mathrm{O}}$, which has nearly the same energy as the $\mathrm{LUMO}+1$ orbital in the intact TFMA ligand. The ratio $A_{\mathrm{C}=\mathrm{C}} /$ $A_{\mathrm{C}=\mathrm{O}}$ (where $A$ is the fitted area under the peaks) decreased as a function of EUV dose as shown in Figure 5. Radical polymerization of $\mathrm{C}=\mathrm{C}$ is one of the major channels leading 


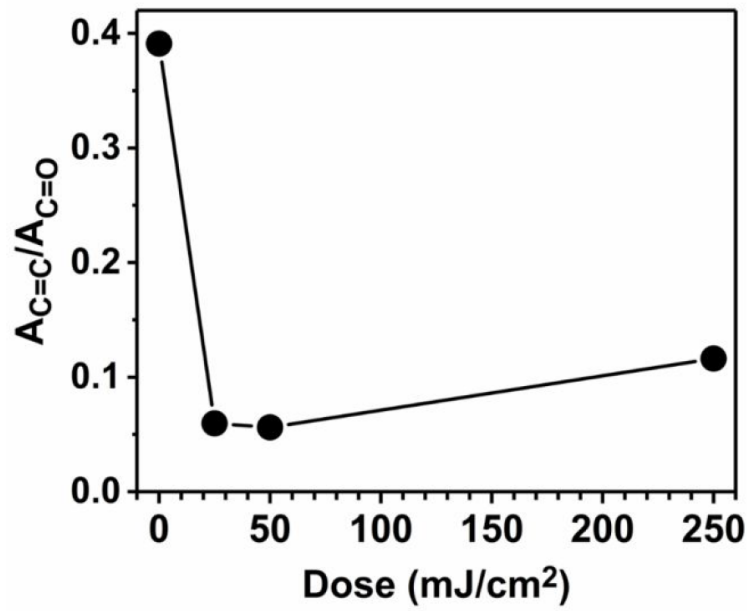

Figure 5. $A_{\mathrm{C}=\mathrm{C}} / A_{\mathrm{C}=\mathrm{O}}$ vs EUV dose for the area under the peaks, $\mathrm{C}=$ $\mathrm{C}$ units $(284.2$ and $284.7 \mathrm{eV}), \mathrm{C}=\mathrm{O}$ units $(286.8$ and $287.9 \mathrm{eV})$ in C(1s) K-edge NEXAFS.

to a significant decrease in the component as a function of dose after decarboxylation reaction. The $\mathrm{C}$ K-edge fitted spectra measured for the exposed area on $\mathrm{Zn}$ (TFMA) thin film are shown in Figure S18. No significant changes were observed in the shape of the recorded $\mathrm{F}$ K-edge spectra as a function of EUV dose (Figure S19).

\subsection{UV-Vis Spectroscopy}

The chemical changes in the material upon EUV irradiation, especially in the $\mathrm{C}=\mathrm{C}$ double bond of the ligand, can be effectively tracked using UV-vis spectroscopy. A decrease in the absorption band at $\sim 190 \mathrm{~nm}\left(\pi \text { to } \pi^{*} \text { transition }\right)^{19}$ was observed as a function of EUV dose, shown in Figure 6a. This bleach can be mainly attributed to the polymerization, in agreement with the STXM results (Scheme 1b). In addition, a simultaneous increase in absorbance around $\sim 275 \mathrm{~nm}$ was observed which can be due to the scattering of light or absorption by the network of oxoclusters/aggregates formed after EUV exposure (Scheme 1a). ${ }^{52}$ Figure $6 \mathrm{~b}$ represents the decrease in $A / A_{0}$ at $\sim 190 \mathrm{~nm}$ as a function of EUV dose. Considering that the absorbance reaches a steady value $A / A_{0} \approx$ 0.55 at high conversion, we can estimate that roughly $69 \%$ of the $\mathrm{C}=\mathrm{C}$ double bonds are converted at the $\mathrm{D}_{50}$ dose (Table 1).

\subsection{Infrared Spectroscopy}

Chemical changes in the organic part of the oxocluster (ligands) upon EUV exposure were further tracked using FTIR. Figure S3 shows the FTIR of Zn(TFMA) oxocluster in powder form and in thin film. The loss of two peaks (marked by asterisks) assigned to $\nu_{\text {as }}$ COO (TFMA) monodentate $\left(1678 \mathrm{~cm}^{-1}\right)$ and $\nu \mathrm{C}=\mathrm{C}($ TFMA $)$ monodentate $\left(1631 \mathrm{~cm}^{-1}\right)$ occurs upon thin film formation. ${ }^{18}$

Figure 7a represents the evolution of FTIR peaks of $\mathrm{Zn}$ (TFMA) thin films as a function of EUV dose. A decrease in the absorbance ratio $A / A_{0}\left(A_{0}\right.$ is the area under the peak of unexposed thin film) of $\nu \mathrm{C}=\mathrm{C}\left(1660 \mathrm{~cm}^{-1}\right.$, Figure $\left.7 \mathrm{~b}\right)$ was observed in agreement with NEXAFS and UV-vis spectroscopy. The conversion at $D_{50}$ is approximately half of the maximum conversion achieved at high dose. Simultaneously, a decrease in the $A / A_{0}$ of $-\mathrm{COO}$ (TFMA, $1678 \mathrm{~cm}^{-1}$ ) was observed with increasing dose due to decarboxylation and outgassing of $\mathrm{CO}_{2}$ upon EUV exposure. $A / A_{0}$ of $\mathrm{C}-\mathrm{F}(1130$ and $1167 \mathrm{~cm}^{-1}$ ) also decreased, as in our previous studies. This is likely due to the formation of $\mathrm{F}^{-}$species formed via dissociative electron attachment (DEA). More details about $\mathrm{C}-\mathrm{F}$ bond cleavage in the organic shell of the oxocluster can be found in the XPS section below. The negative peak at 1100 $\mathrm{cm}^{-1}$ is assigned to $\mathrm{Si}-\mathrm{O}$ bond stretching and is probably the result of a slightly thicker $\mathrm{SiO}_{2}$ layer on the surface of $\mathrm{Si}$ substrate in the reference than in the sample.

In addition, the effect of PEB $\left(120^{\circ} \mathrm{C} / 30 \mathrm{~s}\right)$ on chemical changes was studied using ex situ UV-vis spectroscopy (Figure S21) and FTIR (Figure S22). The effect of PEB depends on the postexposure chemistry. In nonchemically amplified photoresists, PEB sometimes, but not always, results in the improvement of lithography performance. ${ }^{53-55}$ Contrast curve studies presented above revealed a slight decrease in the sensitivity $\left(D_{50}\right)$ of $\mathrm{Zn}$ (TFMA) (MA)(TFA) and $\mathrm{Zn}$ (TFMA) oxoclusters, but this is probably within the margins of error. The UV-vis and FTIR results showed no significant extra decrease in the absorption intensity of $-\mathrm{C}=\mathrm{C}-$ upon $\mathrm{PEB}$ application. The lack of a strong effect of PEB in the present case is consistent with the proposed mechanisms, in which reactive intermediates that would survive ambient conditions do not play a role. For the overall patterning performance, PEB (a)

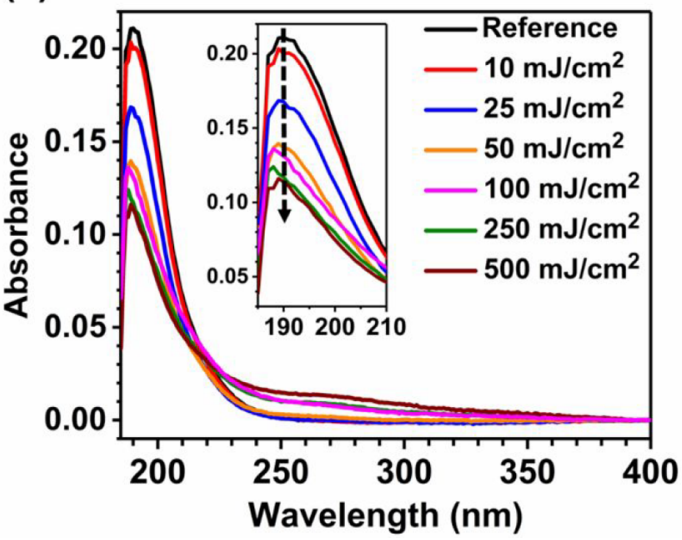

(b)

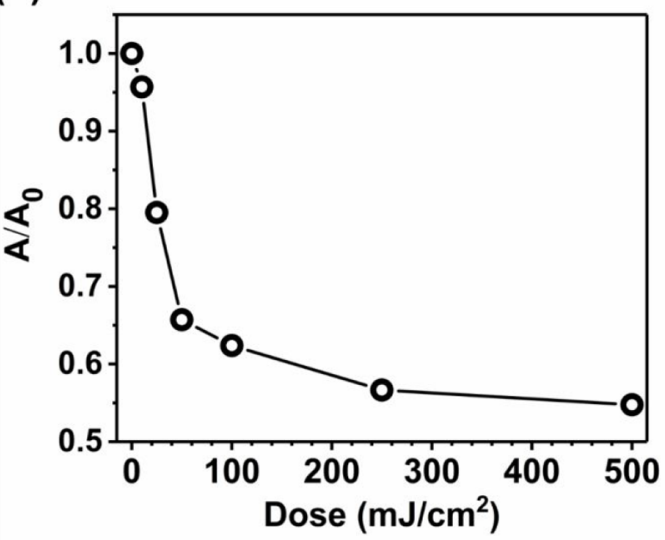

Figure 6. (a) UV-vis spectroscopy on Zn(TFMA) thin film as a function of EUV dose without application of PEB and no development. (b) $A / A_{0}$ at $\sim 190 \mathrm{~nm}$ as a function of dose. 
Scheme 1. Proposed Reaction Mechanisms for Zn(TFMA) Oxoclusters upon EUV Irradiation ${ }^{a}$
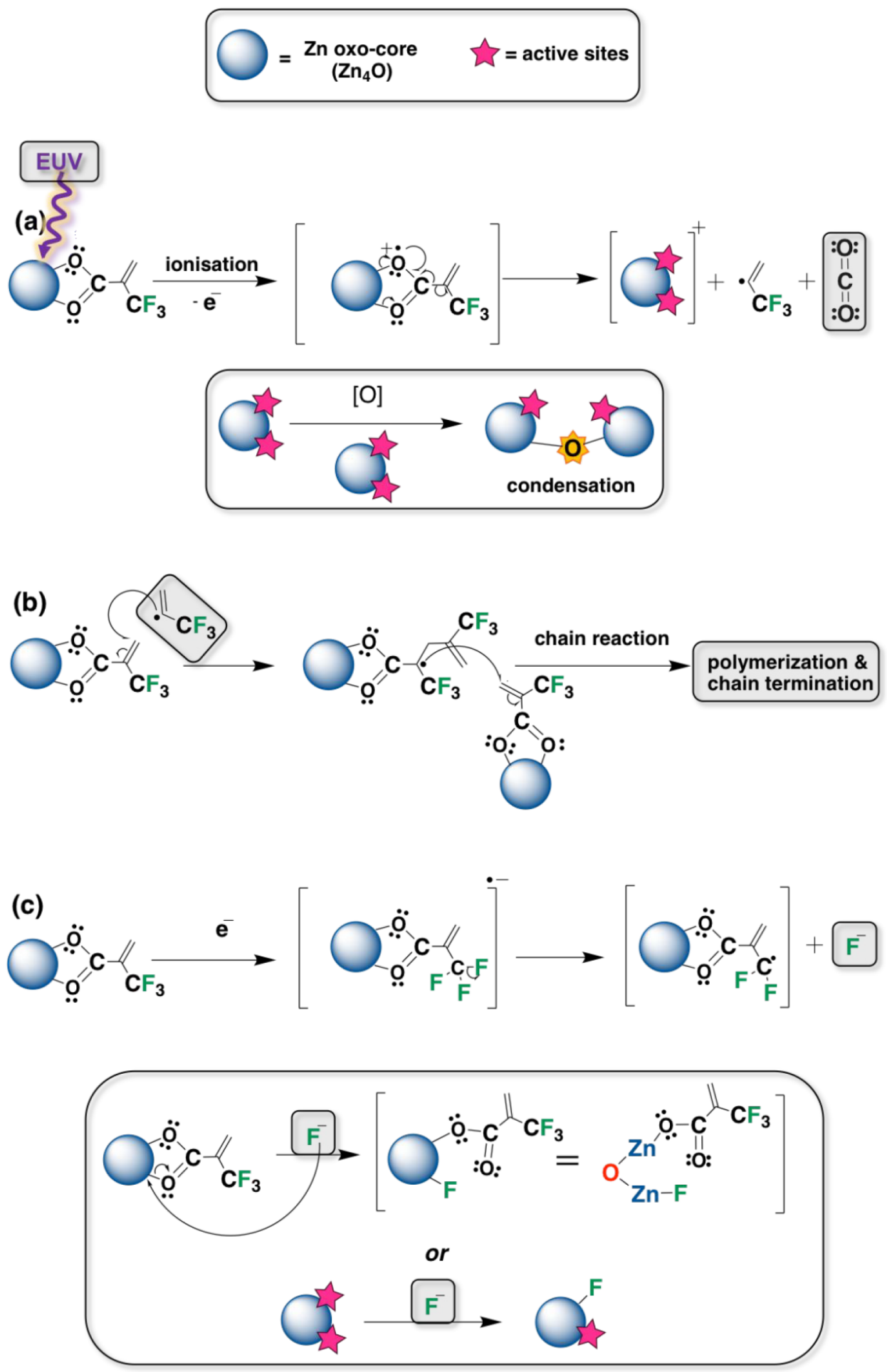

a (a) Ionization of oxocluster followed by decarboxylation reaction and generation of radical and active sites on oxo-core in the thin film, showing condensation reaction between two clusters; (b) radical initiated polymerization of the terminal double bond of TFMA ligand in the thin films; and (c) $\mathrm{C}-\mathrm{F}$ bond cleavage via the DEA pathway, showing the formation of $\mathrm{Zn}-\mathrm{F}$ species.

has a negative effect (increased scumming, Figure S16), probably because of thermal decomposition of the unexposed material. $^{56}$

\subsection{Post-EUV Exposure In Situ XPS}

To investigate the chemical changes induced by EUV irradiation of $\mathrm{Zn}$ (TFMA) in more depth, we combined ex situ spectroscopy studies with in situ X-ray photoelectron spectroscopy. In situ spectroscopy allows avoidance of the chemical changes in the material due to the reaction between the sample and the ambient air, and carbon contamination of the surface. XPS spectra were recorded for $\mathrm{C}(1 \mathrm{~s}), \mathrm{O}(1 \mathrm{~s})$, and $\mathrm{F}(1 \mathrm{~s})$ as a function of EUV dose in a range of $5-500 \mathrm{~mJ} / \mathrm{cm}^{2}$. 
(a)

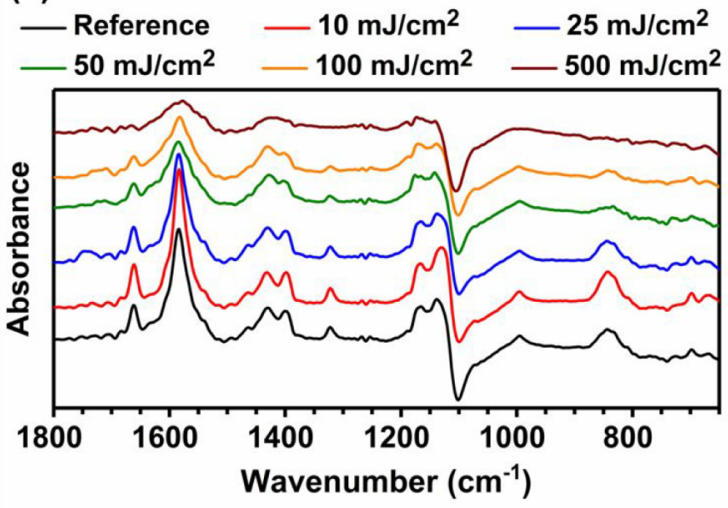

(b)

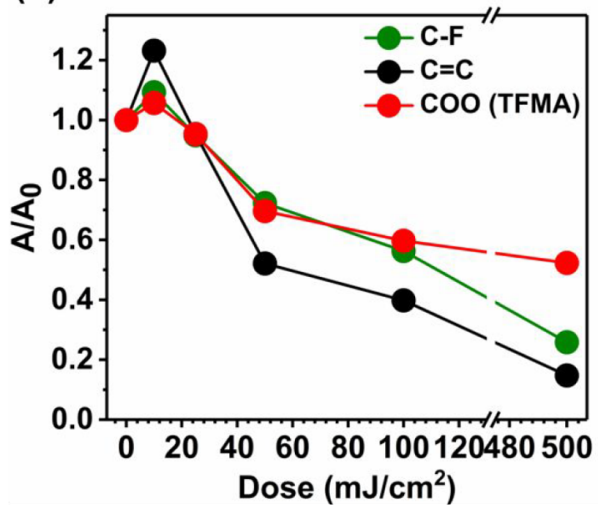

Figure 7. (a) FTIR spectra of the $\mathrm{Zn}$ (TFMA) thin film as a function of EUV dose (no PEB, no development). (b) $A / A_{0}$ as a function of dose for peaks in the spectra shown in (a); C-F $\left(1130-1167 \mathrm{~cm}^{-1}\right), \mathrm{C}=\mathrm{C}\left(1631 \mathrm{~cm}^{-1}\right)$, and COO TFMA $\left(1678 \mathrm{~cm}^{-1}\right)$.
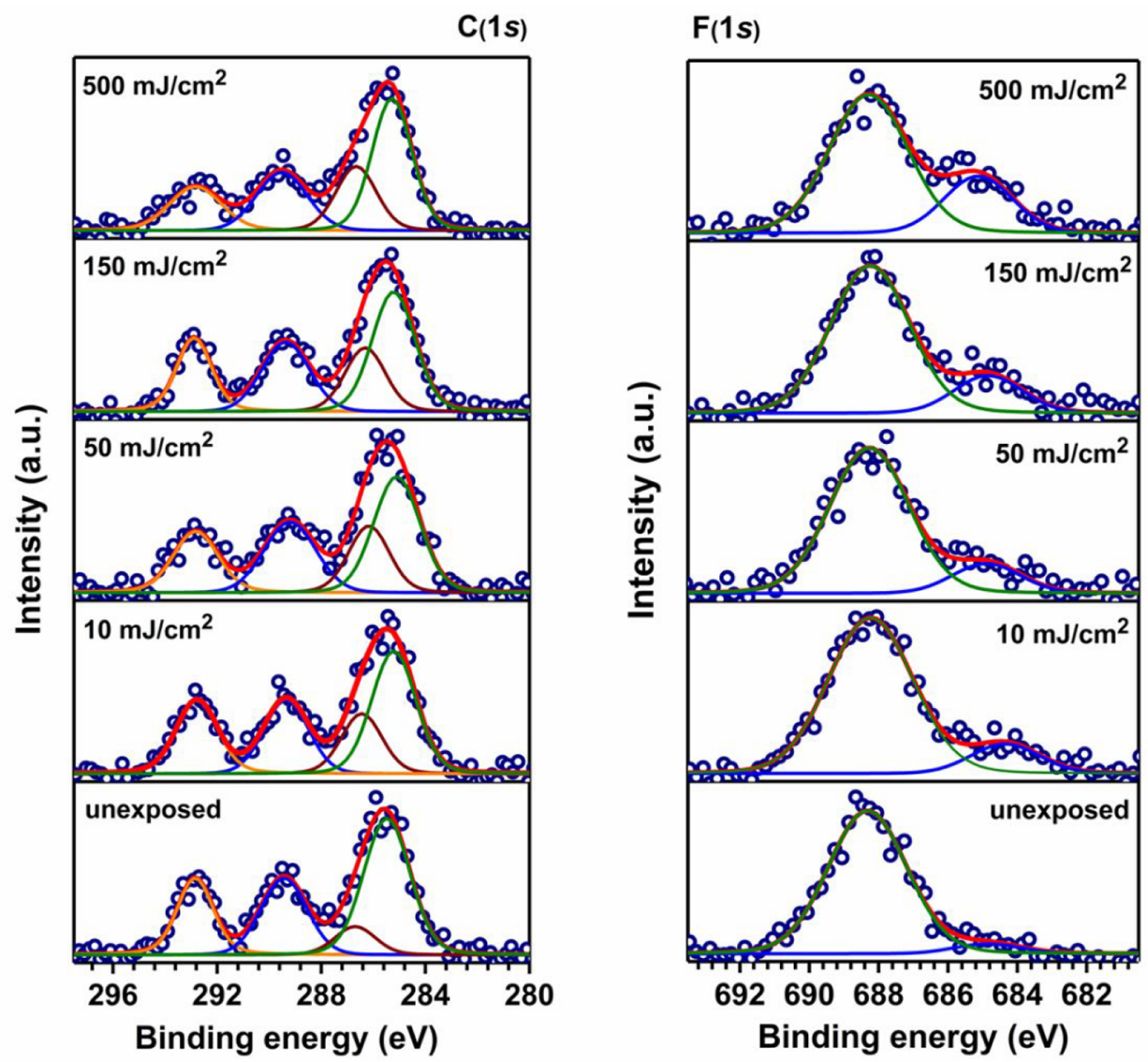

Figure 8. Selected C(1s) and F(1s) XPS spectra recorded as a function of EUV doses with photon energies of 400 and $800 \mathrm{eV}$, respectively. Fresh spots on the thin films were used for each EUV exposure $(\sim 92 \mathrm{eV})$ followed by the XPS measurements.

A film thickness of $15 \mathrm{~nm}$ was measured using AFM on a reference sample spin coated on a Si substrate using the same conditions and same solution. Selected XPS spectra of the $\mathrm{C}(1 \mathrm{~s})$ and $\mathrm{F}(1 \mathrm{~s})$ ranges are shown in Figure 8. The $\mathrm{C}-\mathrm{F}$ peaks at $292.81 \mathrm{eV}$ for $\mathrm{C}(1 \mathrm{~s})$ and $688.21 \mathrm{eV}$ for $\mathrm{F}(1 \mathrm{~s})$ were used as internal references to calibrate the binding energy scale of each spectrum. ${ }^{19}$ The $\mathrm{C}(1 \mathrm{~s})$ spectra can be fitted with four components assigned to $\mathrm{sp}^{2}$ carbon $(285.58 \pm 0.25 \mathrm{eV}), \mathrm{sp}^{3}$ carbon $(286.41 \pm 0.21 \mathrm{eV}),{ }^{57} \mathrm{COO}(289.38 \pm 0.22 \mathrm{eV})$, and $\mathrm{C}-\mathrm{F}(292.81 \pm 0.25 \mathrm{eV}) .{ }^{19}$ The fitted $\mathrm{F}(1 \mathrm{~s})$ spectra have two components assigned to $\mathrm{C}-\mathrm{F}(688.21 \pm 0.19 \mathrm{eV})$ and $\mathrm{Zn}-\mathrm{F}$ $(685.08 \pm 0.24 \mathrm{eV}) .^{19}$
The fitted $\mathrm{sp}^{2}$ carbon component is observed to decrease while the $\mathrm{sp}^{3}$ component increases as a function of increasing EUV dose, in agreement with polymerization of the $\mathrm{C}=\mathrm{C}$ double bonds of TFMA. The fractional area of the components assigned to $-\mathrm{COO}$ and $\mathrm{C}-\mathrm{F}$ in the $\mathrm{C}(1 \mathrm{~s})$ spectra is observed to decrease as well, as a function of EUV dose, signifying the loss of $-\mathrm{COO}$ (outgassing as $\mathrm{CO}_{2}$ ) and $\mathrm{C}-\mathrm{F}$ from the organic shell of the ligand, as shown in Figure 9a.

The F(1s) XPS spectra also reveal a decrease of the $\mathrm{C}-\mathrm{F}$ component (Figure 9b), and a new species assigned to a metal fluoride ( $\mathrm{Zn}-\mathrm{F}$ in this case) was observed. The fractional area of the $\mathrm{Zn}-\mathrm{F}$ species is observed to increase as a function of 

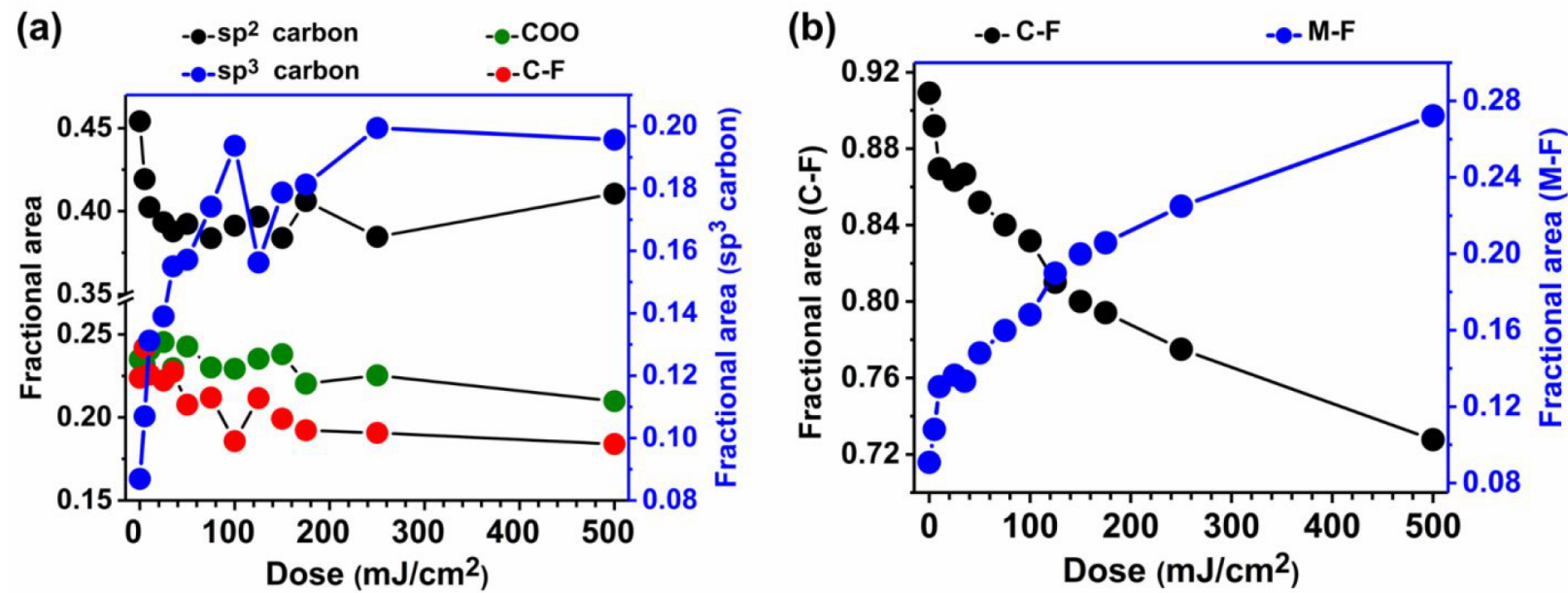

Figure 9. Fractional area of the fitted components as a function of EUV dose in XPS spectra of (a) C(1s), sp ${ }^{2}$ carbon, $-\mathrm{COO}$ and C-F (left axis) and $\mathrm{sp}^{3}$ carbon (right axis); (b) $\mathrm{F}(1 \mathrm{~s})$, two components for $\mathrm{C}-\mathrm{F}$ and M-F.

EUV dose, as also observed in our previous studies. ${ }^{19}$ The decrease in the $\mathrm{C}-\mathrm{F}$ and simultaneous increase in the $\mathrm{Zn}-\mathrm{F}$ is attributed to the migration of fluorine from the organic shell to the $\mathrm{Zn}$-core, shown in Scheme 1c. In addition, the STXM studies also demonstrated no or very little loss of fluorine from the thin film after EUV exposure. The cleavage of the $\mathrm{C}-\mathrm{F}$ bond is induced in the ligand via a well-known path: dissociative ion attachment (DEA) ${ }^{20,58}$ which is a common reaction pathway upon interaction with low energy electrons. The XPS spectra recorded for $\mathrm{O}(1 \mathrm{~s})$ were fitted with only one component (-COO) at a binding energy of $532.13 \pm 0.17 \mathrm{eV}$. As an example, the fitted spectra for the unexposed thin film are shown in SI Figure S23 and the decrease in $A / A_{0}$ for the fitted - $\mathrm{COO}$ component in the $\mathrm{O}(1 \mathrm{~s})$ recorded spectra as a function of EUV dose also points toward decarboxylation, shown in SI Figure S23b.

\subsection{Reaction Scheme}

To summarize the results from all spectroscopy analysis and discussions above, the possible reaction pathways are proposed in Scheme 1. The ionization event of the $\mathrm{Zn}$ (TFMA) oxocluster after EUV photon absorption (Scheme 1a) will likely be followed by decarboxylation, consequently leaving active sites on the $\mathrm{Zn}$-core of the oxocluster and formation of reactive radical species in the thin film. These radical species formed in step (a) can further initiate radical polymerization events in the thin film (cross-linking of the terminal double bond of TFMA) with the neighboring $\mathrm{Zn}$ oxocluster (Scheme 1b). Moreover, the low energy secondary electrons generated in the thin films after the ionization process (a) can induce bond cleavage of $\mathrm{C}-\mathrm{F}$ via well-known DEA process ${ }^{58}$ and parallel generation of radical species in thin films. The XPS studies (section 3.8) clearly indicate the formation of new $\mathrm{Zn}-$ F species after EUV exposure, shown in Scheme 1c.

The main contributor to the solubility switch is the crosslinking between ligands of neighboring clusters. The proposed radical mechanism allows propagation to form extended chains, in competition with termination reactions. Since reactive radicals do not survive long, especially under ambient conditions, the chemical reactions will be finished shortly after exposure, consistent with the lack of a PEB effect.

The different spectroscopic methods applied in the present work agree semiquantitatively on the extent of conversion that is necessary to reach the solubility switch, which is the key property of a photoresist. Differences arise because different measurements were carried out on different samples and under different experimental conditions. Although the spin-coated films were shown to be fairly stable, some aging could not always be avoided, before and after exposure. Despite these quantitative limitations, it is evident that reaching the point of solubility switch, e.g., defined as the $D_{50}$ value (Table 1 ) which is near $40 \mathrm{~mJ} / \mathrm{cm}^{2}$, requires a considerable conversion of the acrylate double bonds, of the order of $50 \%$.

The proposed mechanism allows for multiple reactions per absorbed photon, in other words a quantum yield of reaction exceeding 1: multiple low energy electrons are expected to be generated per photon, each charge separation event can give rise to two reactive species, and the cross-linking reaction proceeds through a radical chain mechanism. A high quantum yield, however, is not guaranteed, because holes and electrons may recombine and the chain propagation may be interrupted by termination reactions. A challenge for future research is to quantify the processes in more detail. In particular, it is important to know how long chains are formed in the crosscoupling, what the termination steps are, and how the length of the chains is related to solubility change. Here, we can make an estimate of the average reaction quantum yield for conversion of the $\mathrm{C}=\mathrm{C}$ bonds. Based on the linear EUV absorption coefficient $(\alpha)$ of $14.3 \mu \mathrm{m}^{-1}$ for $\mathrm{Zn}$ (TFMA), and considering the thickness of the exposed thin film (d) of $\sim 20 \mathrm{~nm}$, the EUV transmittance, $\mathrm{T}=\mathrm{e}^{-\alpha d}$ through the resist is $\sim 75 \%$. Consequently, $\sim 25 \%$ of the photons are absorbed. At the $D_{50}$ value of $40 \mathrm{~mJ} / \mathrm{cm}^{2}$ dose, at least $\sim 50 \%$ of the acrylate double bonds has been converted, based on UV, IR, and XPS measurements. Using the estimated density of $\sim 2 \mathrm{~g} / \mathrm{cm}^{3}$, we find that the ratio of the number of $\mathrm{C}=\mathrm{C}$ bonds converted to the number of photons absorbed is $\sim 10: 1$, which suggests an average quantum yield of $\sim 10$, in agreement with the mechanism.

\section{CONCLUSIONS}

In the present study, we have investigated fluorine-rich $\mathrm{Zn}$ oxoclusters for EUV lithography applications. The results have provided us with the following insights:

Stability and EUV lithography performance: Thin film stability of the fluorine-rich $\mathrm{Zn}$ (TFMA) oxocluster was increased 
compared to its previously studied analogue $\mathrm{Zn}$ (MA)(TFA), while the sensitivity $\left(D_{50}\right)$ for EUV lithography was decreased. The increased stability of the $\mathrm{Zn}$ (TFMA) oxocluster can be mainly attributed to the hydrophobic nature and high electronegativity of the fluorine. The decreased EUV sensitivity of fluorine-rich oxoclusters may arise from several factors: high electronegativity of fluorine slowing down the radical homopolymerization reaction rate; different molecular packing of the oxocluster in the thin-film; and different developer-resist interactions. This study shows that although the incorporation of more fluorine in such systems increases the EUV absorbance, this does not directly translate into higher EUVL sensitivity of the photoresist.

Chemical changes after EUV exposure: A combination of detailed spectroscopic studies shows decarboxylation of the carboxylate ligand upon EUV absorption in the $\mathrm{Zn}$ (TFMA) oxocluster. In addition, a strong decrease of the $\mathrm{C}=\mathrm{C} / \mathrm{C}=\mathrm{O}$ area in STXM-NEXAFS studies as a function of EUV dose supports radical initiated polymerization in the thin film, which is also supported by UV-vis, FTIR, and in situ XPS studies. Furthermore, in situ XPS studies show the formation of new zinc fluoride species in the material upon EUV irradiation via the dissociative electron attachment pathway.

We believe that the present results enhance our understanding of $\mathrm{Zn}$-based fluorine-rich photoresists and similar systems for lithography application and will advance focused investigations for fluorine-rich photoresist materials.

\section{ASSOCIATED CONTENT}

\section{Supporting Information}

The Supporting Information is available free of charge at https://pubs.acs.org/doi/10.1021/acsmaterialsau.1c00059.

Synthesis reaction scheme for $\mathrm{Zn}$ (TFMA), synthesis of $\mathrm{Zn}$ (TFMA)(MA)(TFA) and its thin film deposition, brief description of scanning transmission X-ray microscope; stability study of the thin films of $\mathrm{Zn}$ (TFMA): UV-vis spectroscopy, silanization of the Si substrates, contrast curves for $\mathrm{Zn}$ (TFMA) and $\mathrm{Zn}$ (TFMA)(MA)(TFA) oxoclusters, spin coated thin films of $\mathrm{Zn}$ (TFMA) and $\mathrm{Zn}$ (TFMA)(MA)(TFA) oxoclusters, SEM and AFM images of L/S patterns, STXM-XAS on Zn(TFMA) oxocluster thin films, UV-vis spectroscopy, FTIR spectroscopy, XPS measurement (PDF)

\section{AUTHOR INFORMATION}

Corresponding Authors

Neha Thakur - Advanced Research Center for

Nanolithography, Amsterdam 1098 XG, The Netherlands; (1) orcid.org/0000-0001-5252-0938; Email: n.thakur@ arcnl.nl

Sonia Castellanos - Advanced Research Center for Nanolithography, Amsterdam 1098 XG. The Netherlands; ○ orcid.org/0000-0002-4880-1910; Email: s.castellanos@ arcnl.nl

Albert M. Brouwer - Advanced Research Center for Nanolithography, Amsterdam 1098 XG. The Netherlands; van 't Hoff Institute for Molecular Sciences, University of Amsterdam, 1090 GD Amsterdam, The Netherlands; (1) orcid.org/0000-0002-1731-3869; Email: f.brouwer@ arcnl.nl

\section{Authors}

Michaela Vockenhuber - Paul Scherrer Institute, Villigen 5232, Switzerland

Yasin Ekinci - Paul Scherrer Institute, Villigen 5232, Switzerland

Benjamin Watts - Paul Scherrer Institute, Villigen 5232, Switzerland

Angelo Giglia - IOM-CNR, 34149 Basovizza, Trieste, Italy; (1) orcid.org/0000-0002-1672-9029

Nicola Mahne - IOM-CNR, 34149 Basovizza, Trieste, Italy

Stefano Nannarone - IOM-CNR, 34149 Basovizza, Trieste, Italy

Complete contact information is available at:

https://pubs.acs.org/10.1021/acsmaterialsau.1c00059

Notes

The authors declare no competing financial interest.

\section{ACKNOWLEDGMENTS}

The authors gratefully acknowledge the Paul Scherrer Institute (PSI), Switzerland for the provision of beamtime at XIL-II (proposals 20200726 and 20201570) and at PolLux (proposal 20201561) beamlines of the Swiss Light Source, and ElettraSincrotrone Trieste for beam time at the BEAR end station (proposals 20200400 and 20205228). The authors acknowledge the contribution of Maximillian Paradiz Dominguez, Quentin Evrard and Najmeh Sadegh for their help with conducting synchrotron experiments. The authors also acknowledge Ivan Bespalov for his help with the ATHENA software. Part of the work was carried out at ARCNL, a publicprivate partnership of UvA, VU, NWO, and ASML, and was (partly) financed by "Toeslag voor Topconsortia voor Kennis en Innovatie (TKI)" from the Dutch Ministry of Economic Affairs.

\section{REFERENCES}

(1) Li, L.; Liu, X.; Pal, S.; Wang, S.; Ober, C. K.; Giannelis, E. P. Extreme Ultraviolet Resist Materials for Sub-7 nm Patterning. Chem. Soc. Rev. 2017, 46 (16), 4855-4866.

(2) Ito, T.; Okazaki, S. Pushing the Limits of Lithography. Nature 2000, 406 (6799), 1027-1031.

(3) Wagner, C.; Harned, N. EUV Lithography: Lithography Gets Extreme. Nat. Photonics 2010, 4 (1), 24-26.

(4) Benschop, J. P. EUV Lithography: Past, Present and Future. Proc. SPIE 2021, 11609, 1160903.

(5) De Simone, D.; Vesters, Y.; Vandenberghe, G. Photoresists in Extreme Ultraviolet Lithography (EUVL). Adv. Opt. Technol. 2017, 6 (3-4), 163-172.

(6) Narasimhan, A.; Wisehart, L.; Grzeskowiak, S.; Ocola, L. E.; Denbeaux, G.; Brainard, R. L. What We Don't Know About EUV Exposure Mechanisms. J. Photopolym. Sci. Technol. 2017, 30 (1), 113120.

(7) Kostko, O.; Xu, B.; Ahmed, M.; Slaughter, D. S.; Ogletree, D. F.; Closser, K. D.; Prendergast, D. G.; Naulleau, P.; Olynick, D. L.; Ashby, P. D.; Liu, Y.; Hinsberg, W. D.; Wallraff, G. M. Fundamental Understanding of Chemical Processes in Extreme Ultraviolet Resist Materials. J. Chem. Phys. 2018, 149 (15), 154305.

(8) Ogletree, D. F. Molecular Excitation and Relaxation of Extreme Ultraviolet Lithography Photoresists. Frontiers of Nanoscience 2016, 11, 91-113.

(9) Gallatin, G. M.; Narasimhan, A. K.; Brainard, R. L.; Neisser, M. Chapter 8: Photoresists for EUV Lithography. EUV Lithography 2018, 493-592. 
(10) Neisser, M.; Cummings, K.; Valente, S.; Montgomery, C.; Fan, Y.-J.; Matthews, K.; Chun, J.; Ashby, P. D. Novel Resist Approaches to Enable EUV Lithography in High Volume Manufacturing and Extensions to Future Nodes. Proc. SPIE 2015, 9422, 94220L.

(11) Manouras, T.; Argitis, P. High Sensitivity Resists for EUV Lithography: A Review of Material Design Strategies and Performance Results. Nanomaterials 2020, 10 (8), 1593.

(12) Lawson, R. A.; Robinson, A. P. G. Overview of Materials and Processes for Lithography. In Frontiers of Nanoscience; Elsevier, 2016; Vol. 11, pp 1-90.

(13) Luo, C.; Xu, C.; Lv, L.; Li, H.; Huang, X.; Liu, W. Review of Recent Advances in Inorganic Photoresists. RSC Adv. 2020, 10 (14), 8385-8395.

(14) Sekiguchi, A.; Harada, T.; Watanabe, T. A Study on Enhancing EUV Resist Sensitivity. Proc. SPIE 2017, 10143, 1014322.

(15) De Silva, A. Progress and Challenges of EUV Patterning Material Design. Proc. SPIE 2021, 11609, 116090G.

(16) Neisser, M.; Cho, K.; Petrillo, K. The Physics of EUV Photoresist and How It Drives Strategies for Improvement. J. Photopolym. Sci. Technol. 2012, 25 (1), 87-94.

(17) Trikeriotis, M.; Krysak, M.; Chung, Y. S.; Ouyang, C.; Cardineau, B.; Brainard, R.; Ober, C. K.; Giannelis, E. P.; Cho, K. Nanoparticle Photoresists from $\mathrm{HfO}_{2}$ and $\mathrm{ZrO}_{2}$ for EUV Patterning. J. Photopolym. Sci. Technol. 2012, 25 (5), 583-586.

(18) Thakur, N.; Tseng, L.-T.; Vockenhuber, M.; Ekinci, Y.; Castellanos, S. Stability Studies on a Sensitive EUV Photoresist Based on Zinc Metal Oxoclusters. J. Micro/Nanolith. MEMS MOEMS 2019, 18 (4), 043504

(19) Thakur, N.; Bliem, R.; Mochi, I.; Vockenhuber, M.; Ekinci, Y.; Castellanos, S. Mixed-Ligand Zinc-Oxoclusters: Efficient Chemistry for High Resolution Nanolithography. J. Mater. Chem. C 2020, 8 (41), 14499-14506.

(20) Rohdenburg, M.; Thakur, N.; Cartaya, R.; Castellanos, S.; Swiderek, P. Role of Low-Energy Electrons in the Solubility Switch of Zn-Based Oxocluster Photoresist for Extreme Ultraviolet Lithography. Phys. Chem. Chem. Phys. 2021, 23 (31), 16646-16657.

(21) Christianson, M. D.; Meyer, M. M.; Ongayi, O.; Valeri, D.; Wagner, M. High Absorbing Resists Based on TrifluoromethacrylateVinyl Ether Copolymers for EUV Lithography. Proc. SPIE 2013, 8682, 868216.

(22) Sasaki, T.; Yokokoji, O.; Watanabe, T.; Kinoshita, H. Development of Partially Fluorinated EUV-Resist Polymers for LER and Sensitivity Improvement. Proc. SPIE 2008, 6923, 692347.

(23) Wu, L.; Vockenhuber, M.; Ekinci, Y.; Castellanos Ortega, S. The Role of the Organic Shell in Hybrid Molecular Materials for EUV Lithography. Proc. SPIE 2019, 10957, 109570B.

(24) Henke, B. L.; Gullikson, E. M.; Davis, J. C. X-Ray Interactions: Photoabsorption, Scattering, Transmission, and Reflection at $\mathrm{E}=50-$ 30, 000 EV, Z = 1-92. At. Data Nucl. Data Tables 1993, 54 (2), 181342.

(25) Thakur, N.; Giuliani, A.; Nahon, L.; Castellanos, S. PhotonInduced Fragmentation of Zinc-Based Oxoclusters for EUV Lithography Applications. J. Photopolym. Sci. Technol. 2020, 33 (2), $153-158$.

(26) Patiny, L.; Borel, A. ChemCalc: A Building Block for Tomorrow's Chemical Infrastructure. J. Chem. Inf. Model. 2013, 53 (5), 1223-1228.

(27) Mojarad, N.; Fan, D.; Gobrecht, J.; Ekinci, Y. Broadband Interference Lithography at Extreme Ultraviolet and Soft X-Ray Wavelengths. Opt. Lett. 2014, 39 (8), 2286-2289.

(28) Mojarad, N.; Gobrecht, J.; Ekinci, Y. Interference Lithography at EUV and Soft X-Ray Wavelengths: Principles, Methods, and Applications. Microelectron. Eng. 2015, 143, 55-63.

(29) Raabe, J.; Tzvetkov, G.; Flechsig, U.; Böge, M.; Jaggi, A.; Sarafimov, B.; Vernooij, M. G. C.; Huthwelker, T.; Ade, H.; Kilcoyne, D.; Tyliszczak, T.; Fink, R. H.; Quitmann, C. PolLux: A New Facility for Soft $\mathrm{x}$-Ray Spectromicroscopy at the Swiss Light Source. Rev. Sci. Instrum. 2008, 79 (11), 113704.
(30) Nannarone, S.; Borgatti, F.; Deluisa, A.; Doyle, B. P.; Gazzadi, G. C.; Giglia, A.; Finetti, P.; Mahne, N.; Pasquali, L.; Pedio, M.; Selvaggi, G.; Naletto, G.; Pelizzo, M. G.; Tondello, G. The BEAR Beamline at Elettra. AIP Conf. Proc. 2003, 705 (1), 450-453.

(31) Pasquali, L.; De Luisa, A.; Nannarone, S. The UHV Experimental Chamber for Optical Measurements (Reflectivity and Absorption) and Angle Resolved Photoemission of the BEAR Beamline at ELETTRA. AIP Conf. Proc. 2003, 705 (1), 1142-1145.

(32) CXRO X-Ray Interactions With Matter. http://henke.lbl.gov/ optical constants/ (accessed 2021-04-16).

(33) Fallica, R.; Haitjema, J.; Wu, L.; Castellanos, S.; Brouwer, A. M.; Ekinci, Y. Absorption Coefficient of Metal-Containing Photoresists in the Extreme Ultraviolet. J. Micro/Nanolithography, MEMS, MOEMS 2018, 17 (2), 023505.

(34) Clegg, W.; Harbron, D. R.; Homan, C. D.; Hunt, P. A.; Little, I. R.; Straughan, B. P. Crystal Structures of Three Basic Zinc Carboxylates Together with Infrared and FAB Mass Spectrometry Studies in Solution. Inorg. Chim. Acta 1991, 186 (1), 51-60.

(35) Hiltunen, L.; Leskelä, M.; Mäkelä, M.; Niinistö, L. Crystal Structure of Mu4-Oxo-Hexakis(Mu-Acetato)Tetrazinc and Thermal Studies of Its Precursor, Zinc Acetate Dihydrate. Acta Chem. Scand. 1987, 41a, 548-555.

(36) Jones, R. G.; Ober, C. K.; Hayakawa, T.; Luscombe, C. K.; Stingelin, N. Terminology of Polymers in Advanced Lithography (IUPAC Recommendations 2020). Pure Appl. Chem. 2020, 92 (11), $1861-1891$

(37) Li, R. Q.; Wang, M. X.; Zhang, Q. Y.; Chen, J. G.; Wang, K.; Zhang, X. Y.; Shen, S.; Liu, Z. T.; Liu, Z. W.; Jiang, J. Insight into the Intermolecular Interaction and Free Radical Polymerizability of Methacrylates in Supercritical Carbon Dioxide. Polymers. 2020, 12 (1), 78 .

(38) Ito, H.; Miller, D. C. Radical Copolymerization of 2Trifluoromethylacrylic Monomers. I. Kinetics of Their Copolymerization with Norbornenes and Vinyl Ethers as Studied by in Situ $1 \mathrm{H}$ NMR Analysis. J. Polym. Sci. Part A Polym. Chem. 2004, 42 (6), $1468-1477$.

(39) Ito, H.; Miller, D. C.; Willson, C. G. Polymerization of Methyl A-(Trifluoromethyl)Acrylate and a-(Trifluoromethyl) Acrylonitrile and Copolymerization of These Monomers with Methyl Methacrylate. Macromolecules 1982, 15 (3), 915-920.

(40) Wu, L.; Bespalov, I.; Witte, K.; Lugier, O.; Haitjema, J.; Vockenhuber, M.; Ekinci, Y.; Watts, B.; Brouwer, A. M.; Castellanos, $S$. Unravelling the Effect of Fluorinated Ligands in Hybrid EUV Photoresists by X-Ray Spectroscopy. J. Mater. Chem. C 2020, 8 (42), 14757-14765.

(41) Fallica, R.; Watts, B.; Rösner, B.; Della Giustina, G.; Brigo, L.; Brusatin, G.; Ekinci, Y. Changes in the near Edge X-Ray Absorption Fine Structure of Hybrid Organic-Inorganic Resists upon Exposure. Nanotechnology 2018, 29 (36), 36LT03.

(42) Watts, B.; Ade, H. NEXAFS Imaging of Synthetic Organic Materials. Mater. Today 2012, 15 (4), 148-157.

(43) Watts, B.; Swaraj, S.; Nordlund, D.; Lüning, J.; Ade, H. Calibrated NEXAFS Spectra of Common Conjugated Polymers. J. Chem. Phys. 2011, 134 (2), 024702.

(44) Su, G. M.; Patel, S. N.; Pemmaraju, C. D.; Prendergast, D.; Chabinyc, M. L. First-Principles Predictions of Near-Edge X-Ray Absorption Fine Structure Spectra of Semiconducting Polymers. J. Phys. Chem. C 2017, 121 (17), 9142-9152.

(45) Outka, D. A.; Stöhr, J.; Rabe, J. P.; Swalen, J. D. The Orientation of Langmuir-Blodgett Monolayers Using NEXAFS. J. Chem. Phys. 1988, 88 (6), 4076-4087.

(46) Outka, D. A.; Stöhr, J. Curve Fitting Analysis of Near-Edge Core Excitation Spectra of Free, Adsorbed, and Polymeric Molecules. J. Chem. Phys. 1988, 88, 3539.

(47) Dhez, O.; Ade, H.; Urquhart, S. G. Calibrated NEXAFS Spectra of Some Common Polymers. J. Electron Spectrosc. Relat. Phenom. 2003, 128 (1), 85-96. 
(48) Koningsberger, D. C.; Mojet, B. L.; Van Dorssen, G. E.; Ramaker, D. E. XAFS Spectroscopy; Fundamental Principles and Data Analysis. Top. Catal. 2000, 10 (3), 143-155.

(49) Solomon, D.; Lehmann, J.; Kinyangi, J.; Liang, B.; Heymann, K.; Dathe, L.; Hanley, K.; Wirick, S.; Jacobsen, C. Carbon (1s) NEXAFS Spectroscopy of Biogeochemically Relevant Reference Organic Compounds. Soil Sci. Soc. Am. J. 2009, 73 (6), 1817-1830.

(50) Bagus, P. S.; Weiss, K.; Schertel, A.; Wöll, C.; Braun, W.; Hellwig, C.; Jung, C. Identification of Transitions into Rydberg States in the X-Ray Absorption Spectra of Condensed Long-Chain Alkanes. Chem. Phys. Lett. 1996, 248 (3-4), 129-135.

(51) Sedlmair, J.; Gleber, S. C.; Peth, C.; Mann, K.; Niemeyer, J.; Thieme, J. Characterization of Refractory Organic Substances by NEXAFS Using a Compact X-Ray Source. J. Soils Sediments 2012, 12 (1), 24-34.

(52) Tiwale, N.; Subramanian, A.; Freychet, G.; Gann, E.; Kisslinger, K.; Lu, M.; Stein, A.; Kim, J.; Nam, C.-Y. Hybrid Resist Synthesis by Ex-Situ Vapor-Phase Infiltration of Metal Oxides into Conventional Organic Resists. Proc. SPIE 2021, 11612, 116120A.

(53) Haitjema, J.; Zhang, Y.; Vockenhuber, M.; Kazazis, D.; Ekinci, Y.; Brouwer, A. M. Extreme Ultraviolet Patterning of Tin-Oxo Cages. J. Micro/Nanolith. MEMS MOEMS 2017, 16 (03), 033510.

(54) Ekinci, Y.; Vockenhuber, M.; Terhalle, B.; Hojeij, M.; Wang, L.; Younkin, T. R. Evaluation of Resist Performance with EUV Interference Lithography for Sub-22-Nm Patterning. Proc. SPIE 2012, 8322, 83220W

(55) Kenane, N.; Keszler, D. A. High-Resolution Lithographic Patterning with Organotin Films: Role of $\mathrm{CO}_{2}$ in Differential Dissolution Rates. ACS Appl. Mater. Interfaces 2021, 13 (16), 18974-18983.

(56) Mattson, E. C.; Cabrera, Y.; Rupich, S. M.; Wang, Y.; Oyekan, K. A.; Mustard, T. J.; Halls, M. D.; Bechtel, H. A.; Martin, M. C.; Chabal, Y. J. Chemical Modification Mechanisms in Hybrid Hafnium Oxo-Methacrylate Nanocluster Photoresists for Extreme Ultraviolet Patterning. Chem. Mater. 2018, 30 (17), 6192-6206.

(57) Drewniak, S.; Muzyka, R.; Stolarczyk, A.; Pustelny, T.; Kotyczka-Morańska, M.; Setkiewicz, M. Studies of Reduced Graphene Oxide and Graphite Oxide in the Aspect of Their Possible Application in Gas Sensors. Sensors 2016, 16 (1), 103.

(58) Langer, J.; Stano, M.; Gohlke, S.; Foltin, V.; Matejcik, S.; Illenberger, E. Reactions in Trifluoroacetic Acid $\left(\mathrm{CF}_{3} \mathrm{COOH}\right)$ Induced by Low Energy Electron Attachment. Chem. Phys. Lett. 2006, 419 (1-3), 228-232.

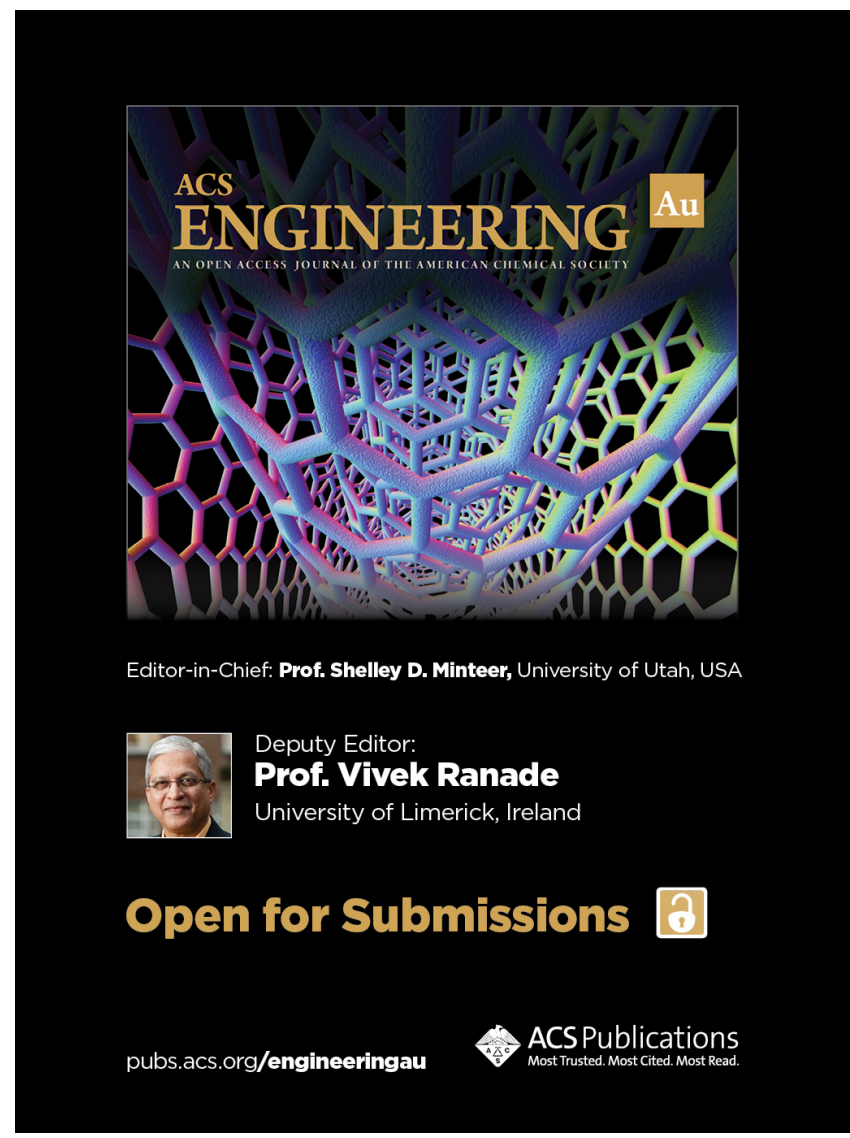

